\title{
Review
}

\section{TIR, CARD and PYRIN: three domains for an antimicrobial triad}

\author{
C Werts ${ }^{1}$, SE Girardin ${ }^{2,3,4}$ and DJ Philpott ${ }^{\star, 1,5}$ \\ 1 Innate Immunity and Signalisation, Institut Pasteur, 28, Rue du Dr. Roux, \\ 75724 Paris Cedex 15, France \\ 2 Unité de Pathogénie Microbienne Moléculaire, INSERM U389, Institut Pasteur, \\ 28, Rue du Dr. Roux, 75724 Paris Cedex 15, France \\ 3 Groupe Inserm Avenir 'Peptidoglycan and Innate Immunity,' Institut Pasteur, \\ 28, Rue du Dr. Roux, 75724 Paris Cedex 15, France \\ ${ }^{4}$ Current address: Department of Laboratory Medicine \& Pathobiology, \\ University of Toronto, Toronto, Ontario, Canada H551A8. \\ ${ }^{5}$ Current address: Department of Immunology, University of Toronto, Toronto, \\ Ontario, Canada H551A8. Tel: 416978 7527; Fax: 416978 1938; \\ E-mail: dana-philpott@utoronto.ca \\ * Corresponding author: DJ Philpott, Institut Pasteur, 28 rue du Dr. Roux, 75724 \\ Paris, France. Tel: + 33-1-45-68-89-93; Fax: + 33-1-45-68-89-53; \\ E-mail: philpott@pasteur.fr
}

Received 30.11.05; revised 24.1.06; accepted 26.1.06; published online10.3.06 Edited by $\mathrm{G}$ Kroemer

\begin{abstract}
Innate immunity to microorganisms in mammals has gained a substantial interest during the last decade. The discovery of the Toll-like receptor (TLR) family has allowed the identification of a class of membrane-spanning receptors dedicated to microbial sensing. TLRs transduce downstream signaling via their intracellular Toll-interleukin-1 receptor (TIR) domain. More recently, the role of intracellular microbial sensors has been uncovered. These molecules include the Nod-like receptors Nod1, Nod2, Ipaf and Nalps, together with the helicase domain-containing antiviral proteins RIG-I and Mda-5. The intracellular microbial sensors lack the TIR domain, but instead transduce downstream signals via two domains also implicated in homophilic protein-protein interactions, the caspase activation and recruitment domain (CARD) and PYRIN domains. In light with these recent findings, we propose that TIR, CARD and PYRIN domains represent the three arms of innate immune detection of microorganisms in mammals.

Cell Death and Differentiation (2006) 13, 798-815.

doi:10.1038/sj.cdd.4401890; published online10 March 2006
\end{abstract}

Keywords: innate immunity; Nod1; Nod2; toll-like receptors; Nalp; pyrin; Ipaf; helicase

Abbreviations: ASC, apoptosis-associated speck-like protein; BS, Blau syndrome; CARD, caspase recruitment domain; DAP, diaminopimelic acid; DC, dendritic cell; FCAS, familial cold autoinflammatory syndrome; FMF, familial mediterranean fever; IBD, inflammatory bowel disease; IFN, interferon; IKK, inhibitor of NF- $\kappa$ B kinase; IL, interleukin; IMCV, IPS-1/MAVS/CARDIF/VISA;
IRF, interferon-regulatory factor; LPS, lipopolysaccharide; LRR, leucine-rich repeats; MDP, muramyl dipeptide; Mur-triLys, $\mathrm{N}$ acetylmuramic acid-L-Ala-g-D-Glu-L-LYS; Mur-triDAP, $\mathrm{N}$-acetylmuramic acid-L-Ala-g-D-Glu-mesoDap; MWS, Muckle-Wells syndrome; NACHT domain, domain present in NAIP, CIITA, HET-E, TP-1; NALP, NACHT-LRR-PYD-containing protein; NOD, nucleotide-binding oligomerization domain; PAMP, pathogen-associated molecular pattern; PBMCs, peripheral blood mononuclear cells (PBMCs); PG, peptidoglycan; PRM, patternrecognition molecule; TIR domain, Toll/interleukin-1 receptor domain; TLR, Toll-like receptor; TNF, tumor necrosis factor; triDAP, L-Ala-g-D-Glu-meso-diaminopimelic acid; SLE, systemic lupus erythematosus

\section{Introduction - The Innate Immune System of Microbial Detection in Mammals}

Innate immunity is the common mode of defense against microorganisms that is present in all animals. In vertebrates, an additional immune system relying on specific detection of particular antigens by subsets of $\mathrm{T}$ or $\mathrm{B}$ cells has been selected by evolution and is termed adaptive immunity. While adaptive immunity allows for the generation of numbers of receptors for microbial antigens through somatic recombination of the genes encoding for the T-cell receptor (TCR) and the immunoglobulin heavy and light chains (giving rise to all classes of antibodies), innate immunity detects microorganisms via a limited set of pattern-recognition molecules (PRMs) transmitted via the germinal lineage. As a result of the paucity of such PRMs in each animal genome, researchers in the field of innate immunity have postulated that these receptors would have been selected by evolution to detect conserved microbial motifs found transversally in a wide range of microorganisms. This hypothesis was also strongly supported by the fact that such relatively invariant structures as lipopolysaccharide (LPS) were known for long to induce considerable responses in the host, ranging from fever to fatal septic shock. During the 20th century, knowledge on the biological effects of microbial-derived invariant structures progressively accumulated. While LPS remained the most widely studied molecule, researchers identified similar biological effects of other microbial signatures, such as hypo-methylated DNA (CpG DNA), peptidoglycan (PG) and lipoproteins from bacteria, or double-stranded RNA from viruses. The wide interest for the study of the biological effects of microbial-derived molecular patterns has been driven by public health threats such as septic shock, which remains a leading cause of morbidity and mortality in western countries. Also importantly, investigations into the molecular basis of host responses occurring in infectious disease have gained substantial understanding from the characterization of the specific responses to conserved microbial motifs. However, 
up until the last decade of the 20th century, the receptors for these microbial motifs that are responsible for triggering biological responses had remained unknown. The light came from a small fly, Drosophila melanogaster.

In the mid-1990s, Lemaitre and Hoffman used a genetic screen to identify mutant flies that were susceptible to infection by the fungus Aspergillus fumigatus. ${ }^{1}$ They identified the receptor Toll as a key mediator of innate immune defenses in Drosophila. Soon after, Medzhitov and Janeway reported the identification of a Toll-like receptor (TLR) in the human genome, which would be later depicted as TLR4. ${ }^{2}$ Then, Beutler and coworkers reported that the long-studied LPSunresponsive mouse strain, $\mathrm{C} 3 \mathrm{H} / \mathrm{HeJ}$, actually carried a mutation in the TLR4 gene. ${ }^{3}$ Following the sequencing of the human and murine genomes, it appears now that mice have 11 TLRs, while human genome contains 10 members, all of which mediate propagation of downstream signals through a common TIR (for Toll/interleukin (IL)-1 receptor) domain. Studies in the past 8 years have allowed the identification of the microbial ligands for most TLRs as well as the signaling pathways downstream of TLRs. These studies are summarized in the Part I of this review. For more extensive description of TLR-mediated innate immunity, readers are encouraged to consult recent reviews on the subject.

Soon after the characterization of TLR-dependent detection of microbes, the existence of TLR-independent modes of detection of both intracellular bacteria and viruses has been postulated. This led to the more recent identification of the nucleotide-binding oligomerization domain (Nod) molecules Nod1 and Nod2 involved in bacterial sensing, as well as the helicases RIG-I and Mda-5 implicated in the cytoplasmic detection of viruses. Interestingly, while all TLRs contain a Toll/interleukin-1 receptor domain (TIR domain), Nods and helicases share a common CARD (for caspase activation and recruitment domain) domain. The role of these CARDcontaining intracellular sensors in innate immunity to bacteria and viruses is presented in the PART II of this review.

Finally, by homology with Nod molecules, a distinct class of Nod-like receptors (NLRs) has been identified in the mammalian genome, which displays a PYRIN domain in the N-terminus; this family is known as NACHT-LRR-PYDcontaining proteins (Nalps) or Pypafs. The direct contribution of Nalps in innate immune detection of microbes remains unclear. However, like TLRs and Nods, Nalps contain a C-terminal LRR domain; moreover, these molecules have a crucial role in the modulation of Caspase-1-dependent inflammation mediated by $\mathrm{IL}-1$ and $\mathrm{IL}-18$. This strongly supports the hypothesis that PYRIN-containing molecules of the Nalp family represent a third branch of an antimicrobial triad, composed of TIR-, CARD- and PYRIN-containing defense molecules. The Part III of this review discusses the role of Nalps in innate immunity.

\section{Part I - TLRs: Signal Transduction through the TIR Domain}

For decades, researchers have documented that various bacteria, fungi and viruses, or products derived from micro- organisms in general, could stimulate mammalian cells and induce the innate production of proinflammatory products. However, it was only after the discovery in 1996 of the role of the Toll protein in defense against microbial infection of Drosophila ${ }^{1}$ did scientists have an inkling that these receptors could also be present in mammals and perhaps have similar functions. Over the last few years, an enormous explosion of research has occurred with the discovery of TLRs in mammals, uncovering their microbial ligands and understanding their function in terms of the generation of the innate and adaptive immune responses. From $<15$ publications in the year 1998, research on Toll and TLRs has grown incredibly to approximately 1200 publications just in the year 2005. In the next sections, we will summarize recent data on TLRs in terms of ligands and ligand recognition, signal transduction and finally look at the link of a number of TLRs associated with human genetic disorders.

\section{Signatures of microbial infection alert the immune system}

To date, 11 TLRs have been described in mammals, with TLR1-9 being common between human and mice and TLR10 present only in humans. TLR11 is only expressed in mice since the gene encoding TLR11 in humans has several stop codons preventing the expression of the protein. Moreover, TLR8 is present in mice but appears to be nonfunctional. ${ }^{4}$ TLRs are all type I integral membrane glycoproteins with an ectodomain characterized by LRR and a cytoplasmic TIR domain. The ectodomain interacts directly or indirectly with the microbial ligand and likely induces receptor clustering, which can be hetero- or homophilic. Cytoplasmic TIR domains are thereby brought together and recruit downstream adaptor molecules to initiate the signaling process.

The ectodomains of TLRs contain 19-25 LRR motifs, which are also found in a number of other proteins with diverse functions, including the ribonuclease inhibitor and the internalin A protein of Listeria monocytogenes. The ectodomain of TLR3 was the first to be crystallized and was shown to form a large horse-shoe-shaped solenoid structure. ${ }^{5}$ In contrast to many LRR-containing proteins, however, the predicted ligand-binding site falls outside the concave surface of the TLR3 horse-shoe. In fact, most of the surface of TLR3, including the concave portion, is masked by carbohydrate, a point that appears to be common to the other TLRs when the location of predicted $\mathrm{N}$-glycosylation sites are examined. ${ }^{5}$ From these data, it seems likely that ligand interaction or interaction with coreceptors likely takes place on one of the major side faces of the TLR3 molecule that is completely devoid of glycosylation.

Cocrystalization data examining the interaction of TLRs with their cognate ligands is still lacking. In fact, there are very few instances where direct interaction between a TLR and its microbial ligand have been demonstrated. In most cases, coreceptors are necessary to make the link between the microbial component and the TLR. For instance, in the case of TLR4, it appears that MD2 is likely the molecule that interacts directly with LPS since this molecule is necessary for the 
discrimination between human and murine lipid A agonists. ${ }^{6}$ In terms of direct interaction, TLR5 likely binds directly with its ligand flagellin. Indeed, a particular domain within the flagellin monomer is recognized by TLR5. $^{7}$ Furthermore, TLR9 appears to interact directly with its ligand, unmethylated CpG oligonucleotide. ${ }^{8}$

As alluded to above, the ligands recognized by TLRs are surprisingly varied. TLR2, in combination with TLR1 or TLR6, and TLR4 recognize lipidated components of the bacterial cell wall; lipoproteins and lipoteichoic acid in the case of TLR2, and LPS for TLR4. A number of endogenous ligands have also been attributed to TLR4, including heat-shock proteins and defensins, however, the possible contamination of these compounds with LPS has still not been ruled out entirely (reviewed by Philpott and Girardin ${ }^{9}$ ).

An interesting study, however, rechallenges the idea that TLRs are only involved in sensing of 'nonself' microbialderived ligands. The work of Jiang et al. ${ }^{10}$ showed that TLR2 and TLR4 drive an inflammatory response to fragments of the extracellular matrix component hyaluronan, which was already known to activate dendritic cells (DCs) through TLR4. ${ }^{11}$ This sugar polymer is broken down by hyaluronidases during injury generating proinflammatory fragments. The authors showed that these fragments induce chemokine production from murine macrophages but this effect is abolished in MyD88-deficient mice, which is an essential adaptor molecule downstream of a number TLRs (see more below). Moreover, their findings show that both TLR2 and TLR4 are required for this proinflammatory response. ${ }^{10}$ Whether these receptors act as heterodimers to enable hyaluronan sensing, however, is still to be determined.

TLR3 recognizes double-stranded RNA released during viral replication. TLRs7, 8 and 9 recognize nucleic acid and what appears to control the immunomodulatory potency of these ligands are methylation and other modifications (reviewed by Ishii and Akira ${ }^{12}$ ). For instance, TLR9 recognizes unmethylated CpG motifs that are often found in DNA from bacteria and viruses but not in eukaryotic DNA. For TLR7 and TLR8, the synthetic nucleoside analog R848 was first shown to be a ligand for these two TLRs. ${ }^{13}$ Recent studies have now shown that single-stranded RNA from viruses and bacteria are also potent agonists. ${ }^{14,15}$ Again, what appears to be a key feature controlling the immunostimulatory capacity of these nucleic acids are modifications of the nucleosides. As in the case for TLR9, methylated RNA, which is more frequently observed in mammalian RNA, is not immunostimulatory towards TLR3, 7 and 8. Moreover, the introduction of modified nucleosides into RNA, like, for instance N6-methyaladanosine or pseudouridine, which are modifications more often observed in mammalian RNA, severely impair inflammatory signaling. ${ }^{15}$

Despite these mechanisms to limit their inflammatory potential, however, host nucleic acids can activate through TLRs and lead to proinflammatory responses. TLR3 can be activated by host mRNA stressing that idea that these TLRs are sequestered in distinct cellular compartments thus avoiding contact with mammalian RNA. ${ }^{16}$ Conversely, RNA that escapes from dead or dying cells is likely to be proinflammatory and may impact on the development of autoimmune inflammation. ${ }^{16}$ Mammalian DNA and RNA, in the form of immune complexes, potently stimulate TLR9 and TLR7, respectively. These findings suggest that TLRs, therefore, play a critical role in the promotion of autoimmune diseases, and in particular, lupus erythematosus. $^{17}$

Only in two cases have TLRs been shown conclusively to be activated by microbial protein ligands. TLR5 recognizes monomeric flagellin, which is the base component of bacterial flagella. ${ }^{18}$ As discussed briefly above, TLR5 is specific for a particular domain within the flagellin structure. ${ }^{7}$ Interestingly, it appears that some bacteria have devised ways of escaping innate immune detection by TLR5. Helicobacter pylori, Campylobacter jejuni and Bartonella bacilliformis, for example, all have modified flagellin structures that are not proinflammatory. ${ }^{19}$ These bacteria have significant sequence divergence within the domain of flagellin previously identified to be critical for TLR5 binding and activation. Furthermore, mutating the Salmonella typhimurium fliC gene to the corresponding $H$. pylori sequence results in a flagellin that is no longer recognized by TLR5. ${ }^{19}$

TLR11 is the other TLR that recognizes a protein ligand, a profilin-like protein from Toxoplasma gondii. ${ }^{20}$ Profilins are a class of small actin-binding proteins that play a regulatory role in actin polymerization. The profilin from $T$. gondii is present in abundance and has high homology to only those profilin proteins from apicomplexan protozoa, which includes the malaria parasite. It will be interesting to examine in the future if profilin proteins from other parasites are similarly recognized by TLR11. Furthermore, we can only speculate for the moment whether TLR11 plays a role in human infections by $T$. gondii. As mentioned above, TLR11 is not present in humans but its expression in mice may influence the carriage of the parasite, which can then transfer the organism to its definitive host, the domestic cat, where it can then infect the human host.

TLR11 has also been implicated in sensing of uropathogenic Escherichia coli, although the ligand is still unknown. TLR11-deficient mice are highly susceptible to kidney infection with this organism. ${ }^{21}$ The physiological relevance remains unknown but it can be speculated that lack of TLR11 expression in humans may favor infection with uropathogenic E. coli.

\section{How microorganisms signal their presence}

TLR-induced signaling results in a variety of cellular responses that include the production of various cytokines, chemokines and interferons (IFNs), and the expression of costimulatory molecules on DCs. These responses of cells driven by TLR stimulation orchestrate both innate and adaptive immune function. The capacity of TLRs to drive these diverse responses derives from their ability to activate different classes of transcription factors, namely NF- $\kappa \mathrm{B}$ and the IFN-regulatory factor (IRF) family members (Figure 1). What has become clear over the years is that TLRs have different capacities to activate these transcription factors and thus induce distinct gene expression profiles from stimulated cells. This induction of tailored responses in cells depending on which TLR is stimulated is underpinned by distinct utilization of adaptor molecules. 




Figure 1 Innate immune detection of microbes occurs at three distinct cellular locations. (1-2) Membrane-spanning receptors of the TLR family are found either located at the plasma membrane (1) or associated with intracellular vesicles (2). In both cases, however, the LRR domain, which is involved in microbial detection, is found in the luminal compartment. (3) Intracellular sensors belong to two distinct groups of molecules. In the first one are found the NLRs, Nod1, Nod2, Ipaf and NALPs. The second one comprises the viral sensors RIG-I and Mda-5. The three groups of sensors recruit adaptor molecules via homophilic interactions (see also Figure 2). TIRdependent signaling leads to the activation of NF- $\kappa$ B, IRFs, as well as other crucial pathways (p38, JNK, ERK) not presented on this scheme for simplification. NLR family members Nod1 and Nod2 are involved in NF- $\kappa$ B and caspase-1 activation. CARD-containing helicases RIG-I and Mda-5 induce both NF- $\kappa$ B and IRF-3 pathways, and the separation point between these two is at the level of IPS-1. CARD-containing NLR Ipaf, as well as Nalps seem to trigger specifically the caspase-1 activation pathway. Activation of NF- $\kappa$ B by lpaf and Nalps has been proposed (see text) but remains controversial and has therefore been omitted on this scheme

Induction of the NF- $\kappa$ B pathway by TLRs

The NF- $\kappa$ B transcription factor is a key mediator that enables the cell to alter the pattern of gene expression in order to quickly respond to changes in the environment. NF- $\kappa \mathrm{B}$ probably plays the most important role in the immune system where it regulates the expression of cytokines, growth factors, and cell adhesion molecules. The proximal signaling events that regulate the activity of NF- $\kappa$ B following TLR and IL-1R stimulation have been well characterized (recently reviewed by Kawai and Akira ${ }^{4}$ ). TLRs and the IL-1 receptor family of proteins share a common cytoplasmic domain, TIR, which allows for the signal to be transduced within the cell. Once activated, the cytoplasmic TIR domains of TLRs interact with other TIR-containing molecules to initiate the signaling event (Figure 1). All TLRs, with the noted exception of TLR3, interact with a common adaptor protein called MyD88. This protein possesses a TIR and a death domain (DD) and acts as a scaffold when bound to the cytoplasmic TIR domain of TLRs in order to recruit downstream signaling factors. For TLR2 and TLR4, an additional coadaptor called MAL or TIRAP is also required for $\mathrm{NF}-\kappa \mathrm{B}$ activation. MyD88 then recruits members of the IL-1R-associated kinases (IRAK) family. IRAK1 becomes phosphorylated, through autophosphorylation but also through the action of IRAK4. Indeed, IRAK4 appears to be essential to this process since IRAK4- but not IRAK1deficient mice are incapable of NF- $\kappa$ B induction following TLR and IL-1R activation (reviewed by Kawai and Akira ${ }^{4}$ ). Moreover, a number of human patients have been identified with IRAK4 mutations and these individuals are severely impaired in their ability to control pyogenic bacterial infections (reviewed by $\mathrm{Ku}$ et al. $^{22}$ ). Phosphorylated IRAK dissociates from the complex, interacts with TRAF6, which then in turn activates TAK1. TAK1 then promotes the downstream induction of the $\mathrm{I} \kappa \mathrm{B}$ kinases, inhibitor of $\mathrm{NF}-\kappa \mathrm{B}$ kinase (IKK)1 and IKK2, leading to the phosphorylation, ubiquitination and subsequent degradation of $\mathrm{I}_{\kappa} \mathrm{B} \alpha$ and release of active $\mathrm{NF}-\kappa \mathrm{B}$.

Surprisingly, however, even in the absence of MyD88, the NF- $\kappa \mathrm{B}$ pathway can be activated in certain instances. LPS-triggered induction of TLR4 in MyD88-deficient mice still results in NF- $\kappa \mathrm{B}$ activation, albeit with delayed kinetics. Moreover, TLR3 also activates the NF- $\kappa$ B pathway and this is completely independent of MyD88. Importantly, this MyD88independent pathway does not support the induction of proinflammatory cytokines but retains the capacity for the induction of IFN-inducible genes and the upregulation of 
expression of costimulatory molecules on DCs (reviewed by Kawai and Akira, ${ }^{4}$ Kawai et al. ${ }^{23}$ and Kaisho et al. ${ }^{24}$ ). Thus, these observations demonstrate the activation of distinct arms of responses downstream of TLR4, in particular: LPS induction of TLR4 results in a fast MyD88-dependent induction of NF- $\kappa \mathrm{B}$ driving the expression of proinflammatory genes and a MyD88-independent pathway, which is also used by TLR3, that results in a slow NF- $\kappa \mathrm{B}$ activation and the induction of IFN-inducible genes and the expression of costimulatory molecules.

The nonclassical MyD88-independent pathway to NF- $\kappa \mathrm{B}$ induction relies on a distinct TIR-containing adaptor called TRIF, also known as TICAM-1. TRIF interacts directly with the TIR domain of TLR3 and indirectly with that of TLR4, through a coadaptor called TRAM, also known as TICAM-2. Both an interaction through TRAF6 and Rip1 appear to be required for TRIF-mediated NF- $\kappa$ B induction (reviewed by Kawai and Akira $\left.^{4}\right)$.

Induction of the IRF pathways by TLRs

The family of IRF transcription factors critically controls the induction of expression of type I IFNs, which include IFN- $\beta$ and IFN- $\alpha$. Type I IFNs are potently antiviral, which is in line with the fact that triggering of the dsRNA receptor, TLR3, rapidly induces their expression. However, bacterial infection, through LPS stimulation of TLR4 and likely other mechanisms, ${ }^{25}$ can also induce IFN production and type I IFN in general play a key role in mediating the adaptive immune response through their ability to stimulate the expression of costimulatory molecules on antigen presenting cells (Figure 1).

TLR3 and TLR4 induce the expression of type I IFN through a pathway independent of MyD88 but relying on TRIF (reviewed by Kawai and Akira ${ }^{4}$ ). TRIF, therefore, is the bifurcation point in the pathway downstream of TLR3 and TLR4 leading to NF- $\kappa$ B activation on one hand and activation of the IRF family of transcription factors on the other (Figure 1). Specifically, TRIF activates IRF3 and IRF7 through the action of two kinases, TBK1 and IKK-I $\left(\right.$ IKK- $\varepsilon$ ) (reviewed by Kawai and Akira ${ }^{4}$ and Moynagh ${ }^{26}$ ). Activation of these two kinases results in the phosphorylation of IRF3 and IRF7, although it is yet unclear if both kinases are required. TBK1 is by and large essential, although IKK- $\varepsilon$ can compensate for IRF3 activation in TBK1-deficient cells. Therefore, there appears to be functional redundancy between the two kinases although restricted expression of one kinase or the other in certain cell types might dictate to which degree the respective kinase plays a role in this pathway. ${ }^{26}$

TLR7 and TLR9 also induce type I IFN but do so through a pathway dependent on MyD88 and IRF7 (Figure 1). These two TLRs are highly expressed on plasmacytoid DC (pDC), which are key producers of type I IFNs. ${ }^{27}$ Importantly, TLR7 and TLR9 are located primarily in the intracellular endosome compartment requiring that their respective ligands, ssRNA and CpG oligonucleotides, also reach this compartment. Indeed, blocking endosomal uptake of TLR7 and TLR9 ligands by blocking acidification prevents induction of the pathway. ${ }^{12}$ What was surprising was how pDCs activate type I IFNs through an MyD88-IRF7 axis while this is not the case in other cells types. It was first believed that the difference was based in the high relative expression of IRF7 in pDCs compared to other cells. However, what now seems to be important is that the MyD88-IRF7 complex is recruited to the endosomal vesicles in these cells, remaining in this compartment for prolonged periods and resisting transfer to lysosomal vesicles. ${ }^{28}$ Indeed, forcing retention of $\mathrm{CpG}$ in conventional DCs also leads to a robust IFN induction. Also recruited to the vesicles are TRAF6, IRAK4 and IRAK1. There is a recent report that suggests that in this signal transduction pathway, IRAK1 may act to phosphorylate IRF7; IRAK1-deficient pDCs are severely impaired in IFN responses to TLR7 and TLR9 ligands. Surprisingly, therefore, IRAK1 may be implicated more in the IRF pathway than the NF- $\kappa$ B pathway downstream of TLR induction. $^{29}$

Another IRF family member called IRF5 has also been implicated in the TLR-signaling pathway. Surprisingly, IRF5deficient mice are severely impaired in generating proinflammatory cytokines downstream of most TLRs. ${ }^{30}$ In fact, IRF5 DNA-binding motifs are found in the promoters of many genes encoding proinflammatory cytokines suggesting that IRF5 might act cooperatively with NF- $\kappa \mathrm{B}$ at target promoters. In terms of signaling, it has not yet been clearly worked out how IRF5 is activated downstream of TLRs. IRF5 associates with MyD88 and TRAF6 and some have suggested that it is exclusively activated in a MyD88-dependent manner. ${ }^{31}$ However, the fact that cytokine induction is also compromised following TLR3 stimulation, which is a TLR that does not require MyD88, challenges this idea. ${ }^{30}$ It will be interesting to see in the next few months the progress made on the elucidation of this pathway.

IRF5 has also been shown to regulate type I IFN induction through stimulation of TLR7. Knock-down of IRF5 expression in cells stimulated with TLR7 ligand results in decreased type I IFN production. ${ }^{31}$ Although this report did not examine whether TLR9 signaling to IFN production was also equally affected in IRF5 knocked-down cells, this might be expected since TLR9 shares similar downstream signaling pathways with TLR7. However, in PDCs, it appears that TLR9 activation leads to normal type I IFN induction in the absence of IRF5. ${ }^{30}$ Future work will certainly clarify these issues.

Phosphorylation of IRF3 and IRF7 induces a conformational change within the molecule revealing the IRF association domain, which is involved in dimerization, and the DNA binding domain. The activated IRFs translocate to the nucleus and bind to IRF motifs in relevant promoters. IRF3 primarily activates the IFN- $\beta$ promoter, with cooperation from NF- $\kappa$ B and also coactivator proteins, CBP and p300. ${ }^{26}$ Once IFN- $\beta$ is produced, it can feedback onto the cell inducing the activation of another transcription factor complex called ISGF3, which is comprised of Stat1, Stat2 and IRF9. ISGF3 then induces the expression of IRF7, which is normally present in very low levels within most cells. IRF7 can then be subjected to phosphorylation by the same mechanism as IRF3 or through the MyD88-dependent pathway downstream of TLR7 and TLR9, leading to activation and subsequent driving of IFN- $\alpha$ and IFN- $\beta$ promoters. In this way, type I IFN activation results 
in a positive feedback loop ensuring high expression of IFN- $\alpha$, IFN- $\beta$ and IFN-inducible genes. ${ }^{26}$

Activation of IRF5, however, does not appear to proceed as it has been shown for the other IRFs. Indeed, phosphorylation by TBK1/IKK- $\varepsilon$ does not lead to activation or nuclear translocation of IRF5. ${ }^{32}$ It is possible that different kinases, inducing the phosphorylation of distinct residues, may control the activation of this transcription factor. Elucidation of these mechanisms, however, awaits further research.

\section{Putting the brake on TLR responses}

Activation of a particular pathway requires a system of counter-balance in order to limit the response and protect the organism from possible damaging effects. In the TLR activation pathway, a number of mechanisms are in place to downregulate the signaling pathway and ultimately shut down the response. In fact, the expression of many of the negative regulators of the TLR pathway are induced by TLR signaling. In addition, there are also viral proteins that specifically target these pathways in a likely attempt to evade innate immune detection.

TLR signaling can be controlled at multiple levels. Soluble receptor antagonists, including soluble TLR2 and TLR4, can interfere with ligand recognition at the cell surface. Moreover, certain transmembrane proteins are also implicated in the negative regulation of TLR activation. ST2 and SIGIRR, both members of the TIR superfamily, and TRAILR, a tumor necrosis factor (TNF)-related apoptosis-inducing ligand receptor, all interfere with TLR signaling. ST2 and SIGIRR sequester essential signaling proteins like MyD88 and MAL (ST2) and TRAF6 and IRAK (SIGIRR) to block normal activation of NF- $\kappa$ B through TLRs (recently reviewed by Liew et $a I^{33}$ ). Interestingly, SIGIRR is highly expressed in the intestinal mucosa and SIGIRR-deficient mice have higher susceptibility to dextran-sulfate sodium-induced colitis stressing the idea that this negative regulator plays a key role in downregulating signals derived from the commensal flora in the intestinal tract. ${ }^{34}$

A number of intracellular negative regulators also exist. Molecules like MyD88short, SOCS1 and IRAKM all act by interfering with specific points in the pathway downstream of TLRs and blocking activation of the NF- $\kappa$ B pathway. MyD88short antagonizes MyD88 and when recruited to the cytoplasmic domain of TLRs, it cannot interact with IRAK4, thus terminating the signal. SOCS1, TOLLIP and IRAKM act similarly and appear to target IRAK1 and inhibit its phosphorylation and subsequent activation. ${ }^{33}$ Other intracellular regulators, including A20 and TRIAD3A, affect the ubiquitinylation state of components of the TLR pathway. A20 is a zinc-finger protein that deubiquitylates TRAF6, preventing its interaction and activation of TAK1 and the subsequent induction of NF$\kappa \mathrm{B}$. On the other hand, TRIAD3A is a RING-finger E3 ligase that promotes the ubiquitination and degradation of TLR4 and TLR9. It seems that TRIAD3 can specifically target only some TLRs to downregulate expression and thereby diminish TLR ligand-induced responses. ${ }^{33}$ For the moment, it is still unclear how and why this E3 ligase only targets certain TLRs and not others and the physiological relevance of TRIAD3A is still unknown.
A recent report has shown that an IRF family member, IRF4, can also act as a negative regulator of TLR signaling. Interestingly, this IRF appears to compete with IRF5 for MyD88 binding and results in a nonproductive interaction that does not lead to cytokine responses. IRF4 seems to be important in dampening signals emanating from TLR9 induction. Indeed, mice deficient in IRF4 are hypersensitive to DNA-induced shock with elevated levels of proinflammatory cytokines present in the serum. ${ }^{35}$

Finally, the viral proteins A46R and A52R from poxviruses can also target TLR-signaling pathways to downregulate inflammatory responses. A52R physically interacts with TRAF6 and IRAK2 whereas the direct target of A46R is still unknown (reviewed by Bowie et $a{ }^{36}{ }^{36}$ ). An interesting area of research in the future will be to examine if other microbial pathogens can interfere with TLR signaling in order to escape immune detection.

\section{Genetic diseases associated with TLR mutations}

As discussed above, TLRs play a key role in the innate immune recognition of invading microorganisms and the subsequent mounting of the immune response. Growing amounts of data suggest that the ability of certain individuals to respond properly to TLR ligands may be impaired by single nucleotide polymorphisms within TLR genes or components of the TLR-signaling pathway, resulting in an altered susceptibility to infectious or inflammatory disease. Indeed, mutations in TLR2, TLR4 and TLR5 and IRAK4 have all been associated with increased susceptibility to a number of infectious diseases. TLR2 mutations have been shown to be more frequent in individuals suffering from the mycobacterial infections, tuberculosis and leprosy, emphasizing the key role of TLR2 in the detection of mycobacterial pathogenassociated molecular patterns (PAMPs) (reviewed by Schroder and Schumann ${ }^{37}$ ). For TLR4, there have been many studies implicating TLR4 mutations in susceptibility to the development of sepsis. Indeed, $\mathrm{C} 3 \mathrm{H} / \mathrm{HeJ}$ mice, which had been known for years to be resistant to LPS-induced shock but highly sensitive to bacterial infection, were shown to have a mutation in the TLR4 gene. ${ }^{3}$ Moreover, increased meningococcal disease has also been associated with TLR4 mutations. For TLR5, a polymorphism that introduces a premature stop codon abolishes flagellin sensing and has been linked to an increased susceptibility of affected individuals to Legionnaire's disease, the causative agent being the flagellated Gram-negative bacterium, Legionella pneumophila. ${ }^{38}$ Furthermore, a wild-derived mouse strain called MOLF/Ei, previously shown to be highly susceptible to Salmonella enterica serovar Typhimurium infection, has decreased TLR5 mRNA compared to C57BL/6J or $\mathrm{C} 129$ mice ${ }^{39} \mathrm{~A}$ number of polymorphisms in the TIr5 gene were identified in this mouse strain but it is yet to be shown if these mutations result in a loss of function of the TLR5 protein. The auto-immune disease, systemic lupus erythematosus (SLE), has also been linked to TLR5 mutations. ${ }^{40}$ Interestingly in this case, TLR5 deficiency is negatively associated with disease. Indeed, the stop codon polymorphism in TLR5 appears to protect individuals from this disease. These findings predict that flagellated bacteria, 
signaling through TLR5, may influence the development of SLE. ${ }^{40}$

\section{Part II - Nods and Helicases: Signal Transduction through the CARD Domain}

Eucaryotic cells have evolved sophisticated mechanisms to sense microbes and signal their presence in order to fight infection. The field of innate immunity has received much attention with the discovery of TLRs and unraveling of their functions and more recently of the cytosolic sensors Nod1 and Nod2 from the domain present in NAIP, CIITA, HET-E, TP-1 (NACHT)-LRR family. This field is blooming again these days with the discovery of intracellular sensors of virus, such as the helicase RIG-I and Mda-5 and their adaptor IPS-1, that upon activation drive the production of type I IFN, involved in the clearance of virus. Interestingly, both Nod proteins and these helicases share a CARD domain.

We will focus here on the PAMPs that are sensed by these CARD proteins and the known molecules involved in the subsequent intracellular signaling and downstream production of cytokines. We will finally mention the different human pathologies associated with dysfunction of these intracellular sensors.

\section{CARD sensors and PAMPS}

\section{Nods and PG motifs}

The first intracellular microbial sensors to be discovered were the Nod1 and Nod2 proteins, from the NACHT-LRR family. These cytosolic sensors are tripartite proteins (Figure 2), composed of one (for Nod1) or two (for Nod2) amino-terminal caspase recruitment domain (CARD), which is involved in downstream signaling, a central nucleotide binding and oligomerization (NACHT) domain and a carboxyl-terminal LRR domain, which is involved in the sensing of ligands. ${ }^{41}$

$P G$ is a potent immuno-stimulatory component of the bacterial cell wall. Originally thought to be a TLR2 agonist, PG activates cells through Nod proteins. ${ }^{42-45}$ TLR2 stimulatory activity of $P G$ can be attributed to contaminating lipoproteins and/or lipoteichoic acid. ${ }^{46}$ This question remains controversial since Dziarski and colleagues published that TLR2 senses soluble PG from Staphylococcus aureus. ${ }^{47}$ In contrast, Inamura and colleagues have synthesized small soluble PG fragments that mimic the soluble PG released by bacteria and clearly show that these PG fragments induce only Nod2 but not TLR2. ${ }^{48}$

$\mathrm{PG}$ is a polymer of carbohydrate chains of $\beta(1-4)$-linked, alternating $\mathrm{N}$-acetylglucosamine $(\mathrm{G})$ and $\mathrm{N}$-acetylmuramic (M) acid sugars crosslinked by short peptides. The nature of

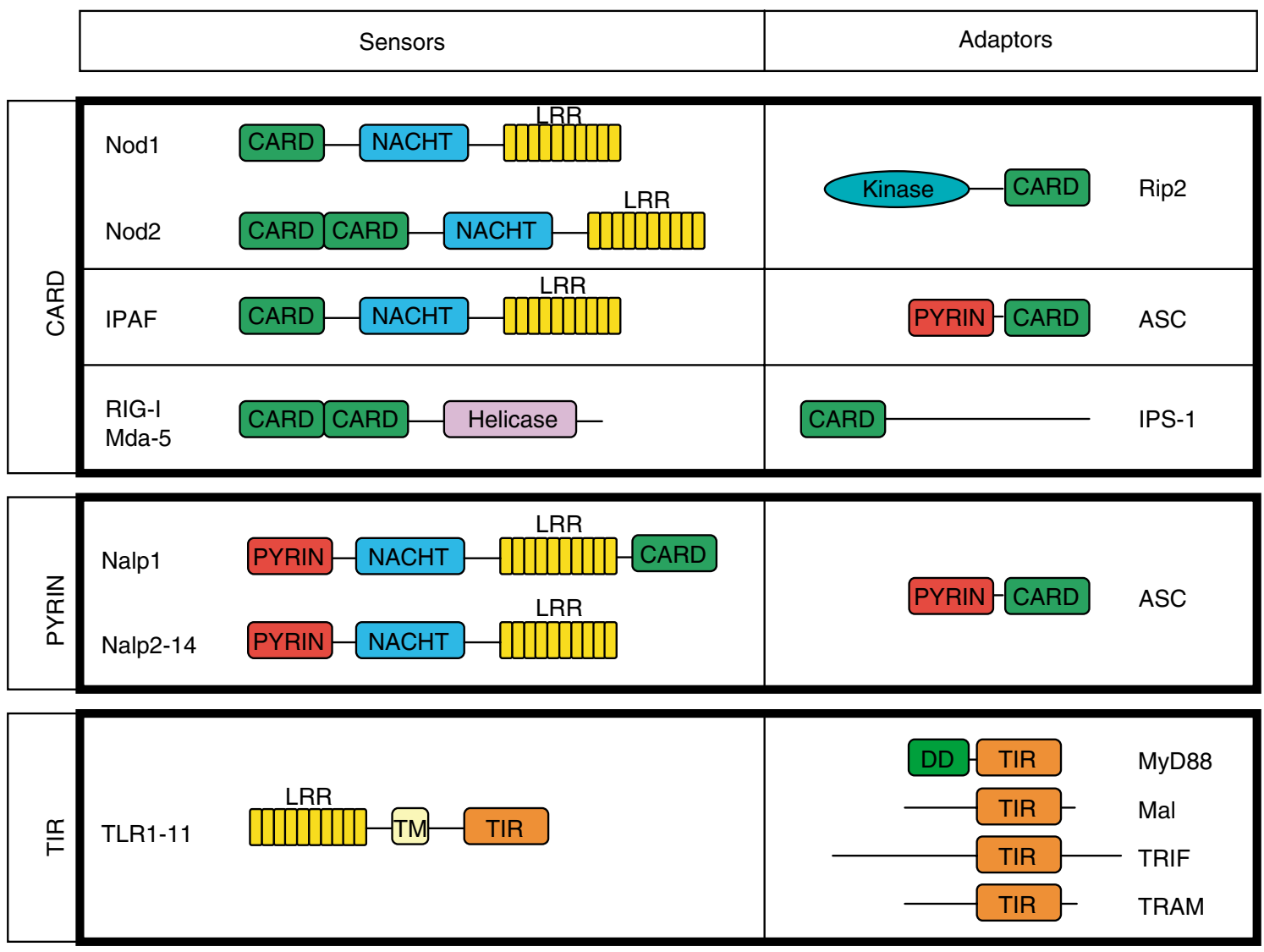

Figure 2 Schematic representation of the innate immune sensors and adaptors displaying CARD, PYRIN or TIR domains. Of note, only two molecules, ASC and Nalp1, have been reported so far to contain two signaling modules, that is, a CARD and a PYRIN domain. A fifth TIR-containing adaptor protein is predicted from the human genome databases but its characterization is still missing; therefore, it has been omitted from the figure. Many CARD-containing molecules do not appear of this figure, such as caspases 1 and 5, Bcl-10 or molecules implicated in TNF signaling (RAIDD); even if the role of these molecules in innate immunity is clear, they have not been implicated directly in microbial sensing. TM, transmembrane domain; see text for other abbreviations 
the third peptide residue of the stem constitutes an important distinct feature of bacterial PGs. While most Gram-negative bacteria have a meso-diaminopimelic acid (DAP) in the third position of the stem peptide, a lysine is found at this position in PG from most Gram-positive bacteria. ${ }^{49}$ In fact, both Nod1 and Nod2 proteins detect muropeptides monomers released by bacterial PG. ${ }^{50}$ Nod2 is a general sensor for both Gramnegative and Gram-positive bacteria since muramyl dipeptide (MDP), the minimal motif common to all PGs, has been shown to be stereo-specifically recognized by Nod2.42,44 MuramyltriLYS ( $N$-acetylmuramic acid-L-Ala-g-D-Glu-L-Lys (Mur-triLYS)) found in Gram-positive $P G$, but not the MuramyltriDAP ( $N$-acetylmuramic acid-L-Ala-g-D-Glu-mesoDAP (Mur-L-Ala-g-D-Glu-meso-diaminopimelic acid (triDAP))) found in PG from Gram-negative bacteria, can be detected as well by Nod2. ${ }^{51}$ Nod1, in contrast, has a narrow specificity and recognizes only DAP-type $\mathrm{PG}$, which constitutes a signature of most Gram-negative bacterial PGs. ${ }^{43}$ Nod1 detects efficiently the naturally occurring muropeptide GM-L-Ala-DGlu-mesoDAP, but the minimal motif found to activate human Nod1 is the dipeptide D-Glu-mesoDAP. ${ }^{45,50}$

Interestingly, species specificity of Nod1 recognition has been shown for the tracheal cytotoxin (TCT). ${ }^{52}$ TCT is a potent immuno-stimulatory compound of the Gram-negative bacterium Bordetella pertussis. Its structure corresponds to a DAPcontaining muropeptide GM-L-Ala-D-Glu-mesoDAP-D-Ala. ${ }^{53}$ Murine Nod1 but not human Nod1 is able to detect TCT, showing that murine Nod1 detects a tetrapeptide structure whereas human Nod1 requires a tripeptide for efficient recognition. ${ }^{52}$ This difference of peptide specificity likely relies on punctual differences between the primary amino-acid sequences of LRR from human and mouse Nod1. ${ }^{54}$

Two different mutagenesis approaches have recently allowed for the identification of the critical residues of the LRR domain of human Nod1 and Nod2 specifically involved in the sensing of muropeptides. ${ }^{54,55}$ First, a systematic mutational analysis of Nod2 has provided insight into the molecular functions of the different domains of the molecule. ${ }^{55}$ Then, a directed mutagenesis of the LRR domain of Nod1 allowed to define a central conserved region within the inner concave face of the LRR, likely responsible for the M-TriDAP detection. $^{54}$

Nod proteins have been shown to play a key role in host defense in response to different bacterial pathogens. Nod1 is involved in host defense towards intracellular pathogens including Shigella flexneri, ${ }^{56}$ enteroinvasive E. coli, ${ }^{57}$ Pseudomonas aeruginosa, ${ }^{58}$ Chlamydiae pneumoniae, ${ }^{59}$ as well as non invasive $H$. pylori which delivers muropeptides within the epithelial cells though its type IV secretion apparatus encoded by the cag pathogenicity island. ${ }^{60} \mathrm{Nod} 2$ is involved in the sensing of Streptococcus pneumoniae ${ }^{61}$ and Mycobacteria. $^{62}$

In vivo studies in mice have shown an important role for Nod2 in bacterial clearance since an increased bacterial load was observed in the liver and spleen of Nod2-deficient mice compared to control mice after oral challenge with L. monocytogenes. ${ }^{63}$ This could be linked to the reduced expression, in Nod2 deficient mice, of a subgroup of intestinal antimicrobial peptides, known as cryptdins. ${ }^{63}$ This is in line with previous in vitro studies, showing decreased intracellular survival of $S$. Typhimurium in human Caco-2 intestinal epithelial cell line, stably expressing Nod2. ${ }^{64}$ A role for human Nod2 in the regulation of antimicrobial peptides is also suggested by studies on Crohn's disease patients. Actually, human $\alpha$ defensins are predominantly secreted by Paneth cells, which are specialized intestinal cells located in the crypts of the ileum. Nod2 is preferentially expressed in myeloid cells but is also expressed in Paneth cells. ${ }^{65}$ Interestingly, a recent study revealed diminished $\alpha$ defensin expression in Paneth cells from Crohn's patients with Nod2 mutations, ${ }^{66}$ suggesting that defective sensing by Nod2 protein could lead to a diminished mucosal protection due to a decreased production of these antimicrobial effectors.

\section{Ipaf and Salmonella}

Ipaf is another member of the NACHT-LRR family. It possesses the same structure as Nod1, with a N-terminal CARD domain, a central NACHT domain and a C-terminal LRR domain. Ipaf is mainly expressed in myeloid cells. Along with apoptosis-associated speck-like protein (ASC), a CARDcontaining adaptor, Ipaf has been involved in the regulation of caspase-1, which is activated within the 'inflammasome,' a complex comprising several adaptors (see Part III of this review) and permitting pro-IL1- $\beta$ processing and secretion of mature IL1- $\beta$ (Figure 1). Although ASC deficiency impairs maturation of $\mathrm{IL}-1 \beta$ in response to TLR and extracellular ATP, TLR-dependent activation of caspase-1 does not require Ipaf. However, Ipaf is essential for caspase-1 activation in response to infection of macrophages by the invasive intracellular pathogen $S$. Typhimurium. Furthermore Ipaf-deficient macrophages are resistant to cell death induced by $S$. Typhimurium. ${ }^{67}$ Whether the unknown ligand of Ipaf is specific to Salmonella or is intrinsic to the intracellular invasion process remains to be determined.

\section{Helicases and double-strand RNA (dsRNA)}

Viruses are recognized by cells through their structural proteins, their hypo-methylated DNA and their single (ssRNA) or double-strand RNA (dsRNA) (see Part I of this review). dsRNA is a key PAMP as it is the hallmark of intracellular replication of many viruses. The first intracellular receptor reported for sensing viral dsRNA was the dsRNA-dependent serine threonine protein kinase (PKR), involved in the control of viral replication by inhibiting host translation initiation. TLR3 was subsequently identified to be a key sensor of dsRNA. Stimulation of TLR3 by dsRNA results in a major release of type I IFN, which constitutes an essential trigger initiating a coordinated defense response to eliminate the virus. PKRand TLR3-independent IFN- $\beta$ production upon infection by virus recently led to the discovery of a new family of intracellular sensors involved in recognition of dsRNA. ${ }^{68}$ These proteins are the DexD/H box RNA helicases retinoic acid-inducible gene I (RIG-I) ${ }^{69}$ and melanoma differentiationassociated gene 5 (Mda-5), also known as Helicard. ${ }^{70}$ Both proteins contain two copies of an $\mathrm{N}$-terminal caspase recruitment domain (CARD), distantly relative to the CARD domains of Nod1 and Nod2, and an RNA helicase domain (Figure 2). The helicase domain recognizes dsRNA and 
regulates signal transduction in an ATPase-dependent manner. ${ }^{70}$ RIG-I, Mda-5 and LPG2, an other member of the DexD/H-box-containing helicase family that lacks the CARD domain, are cytosolic proteins inducible by IFN- $\beta,{ }^{70,71}$ and function independently of TLRs. ${ }^{72}$ The crucial role of RIG-I in virus detection has been demonstrated using RIG-Ideficient murine embryonic fibroblast cells, which do not respond to RNA viruses, included vesicular stomatitis virus, Newcastle virus and Sendai virus. ${ }^{73}$ Mda-5 was initially identified as a molecule with melanoma growth suppressive properties, potentially involved in apoptosis. ${ }^{70}$ It was then shown to be a binding target for protein $\mathrm{V}$ from paramyxovirus, such as Sendai virus. ${ }^{74}$ Protein V interaction with Mda-5, but not with RIG-I, results in the inhibition of IFN- $\beta$ production. ${ }^{71,72,74}$ LPG2 has been identified as a natural specific dominant-negative regulator of RIG-I and Mda-5. ${ }^{71,72}$ It binds dsRNA and can sequester dsRNA away from RIG-I or Mda-5 recognition. ${ }^{72}$ Whether the two helicases RIG-I and Mda-5 have redundant or specific roles remains to be clarified.

Specific structured regions of hepatitis $C$ virus (HCV) genomic RNA have been shown to be ligands for RIG-I. ${ }^{75}$ DsRNA specificity of RIG-I has been assessed using pulldown experiments with beads coupled to synthetic RNA. ${ }^{71,75}$ The respective roles of TLR3 versus RIG-I in the sensing of viral infection through dsRNA recognition, has recently been addressed using RIG-I-deficient mice. Interestingly, RIG-I has been shown to display a crucial role as an intracellular sensor of viral infection, able to initiate a type I IFN response in various cells, but not in pDCs, where TLR3 plays a prominent role. ${ }^{73}$ Many viruses have evolved immune strategies to avoid the type I IFN activation by blocking the pathway at different levels such as PKR, TRIF or IPS-1 (see Gale and Foy ${ }^{76}$ for a review).

\section{Signal transduction downstream of CARD proteins}

Infection of epithelial cells with invasive $S$. flexneri drives an IL-8 response, that relies on Nod1-dependent NF- $\kappa$ B activation. $^{56,77}$. Nod1 and Nod2 stimulation leads also to the production of proinflammatory cytokines as well as JNK activation. ${ }^{56,78}$ Virus infection can activate NF- $\kappa$ B but the prominent cell response is a massive type I IFN release, mediated by the activation of transcription factors, IRF3 and IRF7 (see Part I).

Both Nods, Ipaf and RIG-I and Mda-5 helicases initiate the signal transduction by homotypic interactions with other CARD proteins. Little is known about the mechanism of signal transduction. An intracellular autoinhibitory mechanism is suggested for these CARD domain proteins. ${ }^{55,69}$ It is suggested that the ligand recognition provokes an intracellular conformational change, that exposes the CARD domain, allowing the subsequent recruitment of another CARDcontaining molecule and the signal transduction (reviewed by Kufer et al. ${ }^{41}$ ).

\section{Nods and Ipaf}

Ipaf interacts directly with the CARD domain of procaspase-1 through a CARD-CARD interaction. Mutation K175R in the
NACHT domain of Ipaf abolishes pro-IL1- $\beta$ processing, demonstrating the crucial role of self-association and association with procaspase-1. ${ }^{79}$

In the case of Nods, the sensing of the ligand induces the homo-oligomerization of the Nod molecule, via the NACHT domain, and allows for the recruitment of the CARD domain adaptor RIP2 (RICK/CARDIAK) (reviewed by Kufer et al. ${ }^{41}$ RIP2 is a member of the receptor interacting protein kinase family, and may also be involved in TLR-dependent NF- $\kappa$ B activation $^{80}$ (see also discussion). RIP2 mediates Nod1- and Nod2-dependent NF- $\kappa$ B activation. ${ }^{56,80}$ Upon Nod1 activation, a transient complex between Nod1/RIP2 and IKKs is formed, ${ }^{56,80}$ suggesting a mechanism of downregulation. Recently, it has been shown that activation of Nod2 induces a RIP2-dependent ubiquitinylation of NF- $\kappa \mathrm{B}$ essential modulator (IKK $\gamma$ ), at a novel site, thereby enhancing the NF- $\kappa$ B activation. ${ }^{81}$ In intestinal epithelial cells, membrane recruitment of Nod2 after MDP recognition has been shown to be essential for NF- $\kappa$ B activation. ${ }^{82}$

In contrast to LPS activation, MDP-induced NF- $\kappa$ B activation in human primary mononuclear cells involves NF- $\kappa$ B p50 and p65 subunits, not RelB nor c-rel. ${ }^{83}$ Lack of c-rel subunit involvement in NF- $\kappa \mathrm{B}$ complexes has also been observed in murine splenocytes, stimulated with MDP. ${ }^{84}$ This could have an important implication, since in splenocytes, PG induces an increased IL-12 production in Nod2-deficient mice. ${ }^{84}$ IL-12 transcription is known to specifically require the c-rel subunit translocation, which was accordingly increased in Nod2 deficient cells, upon PG stimulation. ${ }^{84}$ Thus the authors hypothesized that absence of functional Nod2 may lead to disease by causing excessive Th 1 responses, through a dysregulation of c-rel. ${ }^{84}$ However, these data are controversial (see also discussion) and have not been confirmed by others. $^{85}$

Besides NF- $\kappa$ B induction, Nod1 and Nod2 have been shown in early studies to interact with the CARD domain of caspase- 9 and up-regulate caspase- 9 induced apoptosis. Nod1 has also been shown to interact with procaspase-1, enhancing its oligomerization and activation, permitting proIL1- $\beta$ processing and IL1- $\beta$ secretion. This interaction is mediated through heterotypic interactions between CARDs domains of procaspase-1, RIP2, and Nod1 (reviewed by Kufer et $\left.a l .{ }^{41}\right)$. However, further studies are required to clarify the contribution of Nods in the initiation of apoptosis and IL1- $\beta$ secretion, in physiological conditions.

Recent studies revealed that MurtriDAP, the human Nod1 agonist, and MDP, the Nod2 agonist, were both synergizing with pure LPS, the TLR4 agonist, to stimulate pro- and antiinflammatory cytokine production by human monocytes and DCs. ${ }^{78}$ The synergistic cooperation between subactive doses of LPS and Nod agonists induced DC maturation, showing that Nod activation contributes to the onset of adaptive immune responses. ${ }^{78}$ Further examples of synergy between muropeptides and TLR agonists have been reported for cytokine production in human monocytes. ${ }^{83,86-89}$ Cytokines can also synergize with Nod agonists, for the secretion of other cytokines. TNF synergizes with MDP for the secretion of IL- $1 \beta$ by human monocytes. ${ }^{83}$ IL-32, a recently identified proinflammatory cytokine, has been shown to synergize with Nod1 and Nod2 agonists, but not with TLR agonists, for IL-1 $\beta$ 
and IL-6 secretion. Interestingly, the synergy with MDP is specifically blocked by caspase- 1 inhibitors, suggesting a caspase-1-dependent mechanism. ${ }^{90}$ These mechanisms of synergy, requiring a functional Nod protein, ${ }^{83,90}$ remain to be understood, but actually show the crucial role of Nod proteins in cytokine secretion in response to a microbial challenge (see also Discussion section).

Regulators of the NF- $\kappa \mathrm{B}$ Nod-dependent pathways have been recently described. TRIP-6, a LIM-domain-containing protein, can potentiate Nod1 activation, most likely through its interaction with RIP2. ${ }^{91}$ GRIM-19, a protein with homology to the NADPH dehydrogenase complex, interacts specifically with Nod2. GRIM-19 is required for NF- $\kappa \mathrm{B}$ activation following Nod2 recognition of MDP and is necessary for the antibacterial function of Nod2. ${ }^{92}$ Mitogenactivated protein kinase kinase-transforming growth factor$\beta$-activated kinase 1 (TAK1) is an essential component of the signaling pathways of many inflammatory cytokines. TAK1 and Nod2 have been shown to interact through the LRR domain of Nod2 and to reciprocally negatively regulate their NF- $\kappa \mathrm{B}$ activation. ${ }^{93}$ ERBIN, a recently described member of the LAP (LRR and PDZ domain) protein family involved in cell polarity, has recently been identified as a new binding partner of Nod2. ERBIN appears to be a negative regulator of Nod2-dependent NF- $\kappa \mathrm{B}$ and MAP kinases signaling. ${ }^{94}$

\section{Helicases}

Activation of RIG-I and Mda-5 by dsRNA leads to the activation of NF- $\kappa \mathrm{B}$ and IRF3 (Figure 1). Very recently, the missing CARD adaptor linking the RIG-I to the downstream IRF3 and NF- $\kappa$ B activation has been simultaneously identified by four groups and named IFN- $\beta$ promotor stimulator-1 (IPS1) by Akira and co-workers, ${ }^{95}$ mitochondrial antiviral signaling protein (MAVS) by Chen and co-workers, ${ }^{96}$ CARDIF by Tschopp and co-workers ${ }^{97}$ and virus-induced signaling adaptor (VISA) by Shu and co-workers. ${ }^{98}$ This adaptor IPS1/MAVS/CARDIF/VISA (IMCV) has been found in a functional screen ${ }^{95}$ or by research in human protein databases for proteins sharing some homology with the CARD-like modules of RIG-I and Mda-5. Overexpression of IMCV induces type I IFN through IRF3, IRF7 and NF- $\kappa$ B activation. IMCV is required for type I IFN production upon virus infection and dsRNA activation. This activation involves TBK1 and IKKE. The IMCV adaptor is characterized by two domains, a $\mathrm{N}$-terminal CARD domain that interacts with the $\mathrm{N}$-terminal CARD of RIG-I and Mda-5, and a C-terminal effector domain, that recruits FADD and RIP-1. ${ }^{95}$ FADD, a DD-containing protein, and RIP-1 were already known for their crucial role in type I IFN production after virus or dsRNA detection. ${ }^{99}$ Studies with IMCV further showed that this adaptor could physically associate with TLR adaptor TRIF, TRAF2 and TRAF6, that are essential signaling components of the $N F-\kappa B$ pathway induced by viral dsRNA recognition by TLR3. ${ }^{98}$ Interestingly, Meylan et al., ${ }^{97}$ showed that IMCV adaptor was the target and inactivated by NS3/4A a serine protease of $\mathrm{HCV}$ already known to block the RIG-I signaling pathway ${ }^{100,101}$ and inactivate TRIF by proteolytic cleavage. ${ }^{102}$ Finally, the most intriguing feature of this adaptor is that the $\mathrm{C}$-terminal trans- membrane domain, essential for IMCV signaling, targets the protein to the mitochondria. ${ }^{96}$ Although the four groups found the same essential findings, how the signal is transmitted downstream of IPS-1 to the kinases of $N F-\kappa B$ or IRF3 signaling still needs to be clarified.

\section{Diseases associated with CARD-carrying proteins}

Nod2

NOD2 mutations have been associated with several inflammatory granulomatous disorders, such as Crohn's disease, Blau syndrome (BS) and early-onset sarcoidosis.

In the case of Crohn's disease, three major mutations R702W, G908R, and L1007fsinsC have been identified within the LRR region of NOD2. ${ }^{103}$ The NOD2 frameshift $1007 \mathrm{fs}$ mutation (NOD2fs also called 3020insC) is the most prevalent in Crohn's disease patients. This mutation has been shown to abrogate PG and MDP sensing. ${ }^{42,44,83}$ Interestingly, human monocytes from Crohn's patients, homozygotes for the NOD2fs mutation, which do not respond to MDP, do not respond either to Nod1 agonists, revealing an unexpected crosstalk between Nod2 and Nod1 signaling pathways. ${ }^{104}$ NOD2fs monocytes are also impaired in IL1- $\beta$ secretion upon MDP or PG stimulation. ${ }^{83,105}$ In addition, impaired antiinflammatory IL-10 secretion in NOD2fs human monocytes stimulated by TLR2 ligands or whole bacteria has been reported. ${ }^{106}$ These NOD2fs phenotypes suggestive of a 'loss of function' are difficult to reconcile with the massive inflammation observed in Crohn's disease patients. However, macrophages from mice expressing, instead of Nod2, a murine version of the human NOD2fs, exhibit an unexpected 'gain of function' phenotype with increased NF- $\kappa$ B and more efficient processing and IL1- $\beta$ secretion upon MDP stimulation. ${ }^{107}$ Although these results would fit with the global increased inflammation observed in Crohn's patients, they are in discrepancy with those obtained with human NOD2fs monocytes or with macrophages from mice deficient for Nod2 that have been shown to be impaired in MDP sensing and synergy with TLRs. ${ }^{85}$ More studies will be needed to understand these striking discrepancies. See also Discussion and Kufer et al. ${ }^{41}$ for more detailed discussion about these conflicting results.

Interestingly, NOD2 mutations associated with Crohn's disease have been also associated to increased risk of acute graft-versus-host disease and complications following allogenic stem cell transplantation. ${ }^{108}$

BS, a rare autosomal dominantly inherited disease, and early-onset sarcoidosis share characteristic clinical features of juvenile onset and a systemic granulomatosis syndrome, affecting the skin, joints and eyes. ${ }^{63}$ Recurrent mutations in the central NACHT domain from NOD2 have been linked with these diseases. ${ }^{109}$ Compared to wild-type NOD2, the most frequently found mutation, $R 334 \mathrm{Q}$, leads to increased basal $\mathrm{NF}-\kappa \mathrm{B}$ activation, in the absence of ligand, ${ }^{51}$ and further increased NF- $\kappa$ B activation upon MDP stimulation. ${ }^{55}$ Noticeably, Crohn's disease and BS are both characterized by a granulomatosis disorder, but mutations in NOD2 associated with these diseases have opposite effects on the NF- $\kappa \mathrm{B}$ activation. 
Nod1

Polymorphism in NOD1 has been recently associated with genetic predisposition to inflammatory bowel disease (IBD), ${ }^{110}$ asthma ${ }^{111}$ and atopic eczema. ${ }^{111,112}$

A first study looking at polymorphism in exons of NOD1 concluded that NOD1 did not play a major role in genetic susceptibility to IBD. ${ }^{113}$. However, a second group identified two alleles of an insertion-deletion polymorphism near the beginning of the ninth intron of NOD1, strongly associated with IBD, ${ }^{110}$ elevated serum IgE levels and asthma. ${ }^{111}$ Another independent study on atopic eczema and asthma concluded that NOD1 polymorphisms and haplotypic combinations are important determinants of atopy susceptibility. ${ }^{112}$ LRR domain of Nod1 molecule is composed of 10 LRR encoded by exons IX-XIV. It is proposed that the insertion/ deletion mutation found in the ninth intron might affect the relative abundance of different naturally occurring splice variants of Nod1. ${ }^{111}$ The Nod1 splice variants lead to 'incomplete' LRR domains progressively lacking the LRR7 to $9 .{ }^{111}$ Interestingly, these different splice variants have been tested in vitro and showed impaired $\mathrm{NF}-\kappa \mathrm{B}$ activation upon Tri-DAP stimulation, the human Nod1 agonist. ${ }^{54}$ Thus, similar to what has been found for Nod2, a 'loss of function' of Nod1, would be linked to increased susceptibility to IBD or allergic disorders.

\section{Rig-I}

No human disease has yet been linked to RIG-I. However, interestingly, a recent work revealed that the defective host response of a human hepatoma cell line, found highly permissive to $\mathrm{HCV}$ virus replication, was due to a single mutation (T55I) within the first CARD domain of RIG-I, causing a loss of IRF3 signaling. ${ }^{75}$

\section{Part III - Nalps: Signal Transduction through the PYRIN Domain \\ PYRIN}

The PYRIN domain, similar to the CARD domain, is a module containing six antiparallel $\alpha$-helices that form a compact bundle known as the DD-fold; a similar modular structure is also found in DD and death-effector domain. ${ }^{114}$ The founding member of the family of PYRIN-containing proteins is Pyrin (also known as Marenostrin), a molecule whose gene is mutated in families with familial Mediterranean fever (FMF), an heritable autoinflammatory syndrome. ${ }^{115}$ Targeted disruption of Pyrin in mice has been reported by Chae et al., ${ }^{116}$ resulting in the expression of a truncated Pyrin protein harbouring the full PYRIN domain, a situation similar to what is found in FMF patients. Interestingly, Pyrin-truncated mice were found to be hypersensitive to LPS shock and macrophages from these mice produced higher levels of IL-1 $\beta$ in response to LPS stimulation. By this way, the authors could identify a function of Pyrin as an inhibitor of the caspase-1/ IL- $1 \beta$ axis, acting by titrating the adaptor molecule ASC (see below) out of the pathway. ${ }^{116}$ However, more recently Cryopyrin and Pyrin have been shown to activate caspase-1, but not NF- $\kappa \mathrm{B}$, via ASC oligomerization. ${ }^{117}$

\section{ASC}

The adaptor protein ASC has a bipartite domain structure consisting of an N-terminal PYRIN domain and a C-terminal CARD domain. As a consequence, it can be anticipated that ASC represents a key adaptor molecule connecting PYRINand CARD-dependent pathways. It is well established that ASC is an important mediator of caspase-1 activation, and an homophilic CARD-CARD interaction between ASC and procaspase-1 has been reported. ${ }^{118}$ Accordingly, macrophages from ASC-deficient mice are defective in caspase-1 activation (and IL-1 $\beta$ secretion) in response to TLR stimulation or activation by the Gram-negative bacterial pathogen, $S$. typhimurium. ${ }^{67}$ The role of ASC in the activation of the NF- $\kappa$ B pathway remains somewhat controversial. However, LPS- or TNF-mediated activation of NF- $\kappa \mathrm{B}$ was found normal in macrophages from $\mathrm{ASC}^{-1-}$ mice, which argues against a key role of ASC in mediating NF- $\kappa$ B signaling. Several reports point to a role of ASC in Ipaf-dependent pathways. Importantly, two recent studies from Mariathasan et al. ${ }^{67}$ suggest that the Ipaf-ASC axis represents a crucial pathway linking detection of intracellular bacteria and caspase-1 activation. In the first report, the authors demonstrate that Ipaf is essential for Salmonella-dependent activation of caspase-1; they also show that macrophage cell death induced by the bacteria is dependent on ASC and Ipaf. However, investigation of the response of $\mathrm{ASC}^{-1-}$ or Ipaf ${ }^{-1-}$ mice to oral infection with Salmonella was not reported. Similarly, the same group identified a role for ASC in the response to another Gram-negative bacterial pathogen, Francisella tularensis. ${ }^{119}$ However, surprisingly, Ipaf was found to be dispensable for Francisella-mediated induction of the ASC pathway leading to caspase-1 activation. The molecule involved in the detection of Francisella upstream of ASC remains therefore unknown.

\section{Nalps}

Nalp molecules (also known as Pypafs) form a subclass of PYRIN-containing molecules that, in addition to the $\mathrm{N}$-terminal PYRIN, also possess a central NACHT domain flanked by a C-terminal LRR domain. The human genome contains 14 Nalps that share this domain organization; only Nalp1 differs slightly from this architecture, with a CARD domain being found at the C-terminus end of the molecule. Nalps are cytoplasmic molecules, and because their modular domain organization resembles that of Nod1/Nod2, Nalps have been classified with Nod1, Nod2 and Ipaf in the family of mammalian NACHT-LRR containing proteins, also known as NLRs. ${ }^{41}$

For most of them, the function of Nalps remains unknown. Two Nalp family members, Nalp6 (Pypaf5) ${ }^{120}$ and Nalp12 (Pypaf7 or Monarch-1) ${ }^{121}$ have been shown to activate the $\mathrm{NF}-\kappa \mathrm{B}$ pathway. However, others have reported that Monarch-1 dampens NF- $\kappa$ B signals triggered by TLRs or TNF stimulation. ${ }^{122,123}$ In the past few years, the group of Tschopp has pioneered research on the role of Nalps in shaping and regulating caspase-1-triggering complexes, the so-called 'inflammosomes.' 124 The Nalp1 inflammosome induces the activation of both caspase-1 and -5 , through formation of 
a complex containing, in addition to these two caspases, the proteins Nalp1 and ASC. ${ }^{125}$ Similarly, the Nalp2/Nalp3 inflammosome is involved in the activation of caspase-1 (but not caspase-5) through the recruitment of Nalp2, Nalp3, ASC, Cardinal and caspase-1. ${ }^{126}$ Therefore, Nalps appear to represent central regulators of caspase- 1 activation, which in turn controls the release of IL-1 $\beta$, a key cytokine implicated in inflammatory processes. The crucial role played by Nalps in inflammation has been highlighted by the identification of NALP3 mutations, all found in the NACHT domain, associated with the onset of several inflammatory disorders in humans: Muckle-Wells syndrome (MWS), familial cold autoinflammatory syndrome (FCAS) and chronic infantile neurologic cutaneous and articular disease. ${ }^{127}$ Mutations in NALP3 correlate with increased basal levels of released IL-1 $\beta$ from monocytes of patients, suggesting that mutated $N A L P 3$ represent constitutively active forms of the molecule. ${ }^{127}$ Interestingly, R260W, the most common mutation found in MWS and FCAS, is found at an amino acid position that exactly aligns with mutations R334W and R334Q of NOD2 associated with the onset of $\mathrm{BS}$, a rare autosomal-dominant inflammatory disorder; ${ }^{128}$ similarly to the NALP3 mutations, it has been proposed that BS-associated NOD2 mutations lead to a constitutively active molecule. ${ }^{63}$

An important challenge for the coming years will be to identify how Nalp inflammosomes are activated. Martinon et al. $^{125}$ reported that rupture of cellular integrity during cell lysis is sufficient to trigger the Nalp1 inflammosome, suggesting that endogenous host factors may act as danger signals to trigger Nalp activation. In addition, the same group has recently proposed that MDP from bacterial PG, in addition to activating Nod2, was involved in Nalp3 activation (see also the Discussion section). ${ }^{129}$ Since a large number of Nalp proteins exist in mammalian genome, one might predict that these various Nalp family members contribute to the integration of multiple signals leading to the activation of the caspase1-dependent pathway. Indeed, using Nalp3 knockout mice, three groups recently reported a role for Nalp3 in innate immunity. Strikingly, the three groups found different stimuli responsible for Nalp3 dependent caspase-1 activation; that is bacterial RNA, ${ }^{130}$ bacterial toxins and ATP ${ }^{131}$ and uric acid crystals. ${ }^{132}$ More studies will be required to elucidate if: (i) multiple signals are actually sensed by Nalp3, (ii) Nalp3 is an adaptor downstream of a yet-to-be discovered PRR, and (iii) these different stimuli would trigger the same 'danger' signalactivating Nalp3, such as potassium efflux as suggested by Dixit and co-workers. ${ }^{131}$

\section{Discussion - Convergences in the TIR/CARD/PYRIN Triad}

While in Parts I-III of this review we have presented TLR-, Nod- and Nalp-mediated innate immunity as independent modules, evidence suggests that the three branches of the TIR/CARD/PYRIN triad are interconnected, and that an integrative signal contributes to host defense against microorganisms (Figure 3). Examples of such crosstalk remain the exception rather than the rule at present time; however, one can assume that an efficient system for clearance of microbial intruders would gain strength and reliability from an integrated approach. Consequently, we predict a great expansion of our knowledge on the links among these signaling pathways in the coming years. We will review in the next paragraphs most of what is known so far in terms of signaling connections between TLR, Nod and Nalp pathways.

\section{Rip2/TLR}

Rip2-deficient animals were shown to display defective TLR signaling in response not only to LPS but also to lipoteichoic acid, PG and dsRNA, suggesting that Nod pathways connect TLRs at the level of the adaptor molecule Rip2. ${ }^{80}$ However, these results must be taken with caution for the following reasons: (a) the studies have been performed on nonbackcrossed animals, (b) the microbial molecules used have not been shown to be devoid of muropeptides, the specific Nod agonists. Also suggestive of a role for Rip2 in TLR signaling was the recent implication of this molecule in LPS-mediated signaling in macrophages; but, again, the LPS used in the latter study was from a commercial source and had not been tested for the possible presence of muropeptide contaminants. Therefore, one could argue that in both cases, the authors observe synergistic effects emanating from the TLR and Nod pathways (see below).

\section{Nods/TLR}

Several recent reports have investigated the possible role of either Nod1 or Nod2 in TLR-driven signaling by using macrophages isolated from Nod-deficient animals. In the case of Nod2, results from three independent groups, working on either nonbackcrossed or backcrossed animals demonstrate that Nod2 is dispensable for full TLR signaling in murine macrophages. ${ }^{84,85,107}$ Similarly, studies from our group on macrophages from backcrossed Nod1 knockout mice reveal that Nod1 deficiency does not impair the ability to respond to TLR ligands such as LPS or lipopeptide.

The data reported above suggest that TLR can function independently from Nods, at least for the cytokines tested in these studies. Saying that, these results do not imply that TLR- and Nod-dependent pathways are fully independent. Indeed, a considerable body of evidence shows that TLR and Nod ligands act in synergy to trigger diverse cellular responses, such as cytokine secretion or expression of costimulatory molecules. Most of our knowledge has accumulated on the synergistic effect of MDP on LPS-driven responses, but evidence exists also for a synergy between MDP and other TLR agonist (see also Part II). In the case of the synergy between Nod1 and TLR agonists, the reports are less abundant, mostly because MurtriDAP (or related DAPcontaining muramyl peptides that activate Nod1) are more difficult to purify than MDP. Nonetheless, as for MDP, it is well documented that Nod1 agonists act in synergy with LPS and other TLR-triggering molecules (see Part II).

The molecular basis of the synergistic effect of Nod agonists on TLR-mediated cytokine responses remains largely unclear. The following observations could account for the actual TLR/Nod synergy: (i) LPS stimulation upregulates Rip2 expression in murine macrophages, ${ }^{80}$ (ii) TAK1, a 


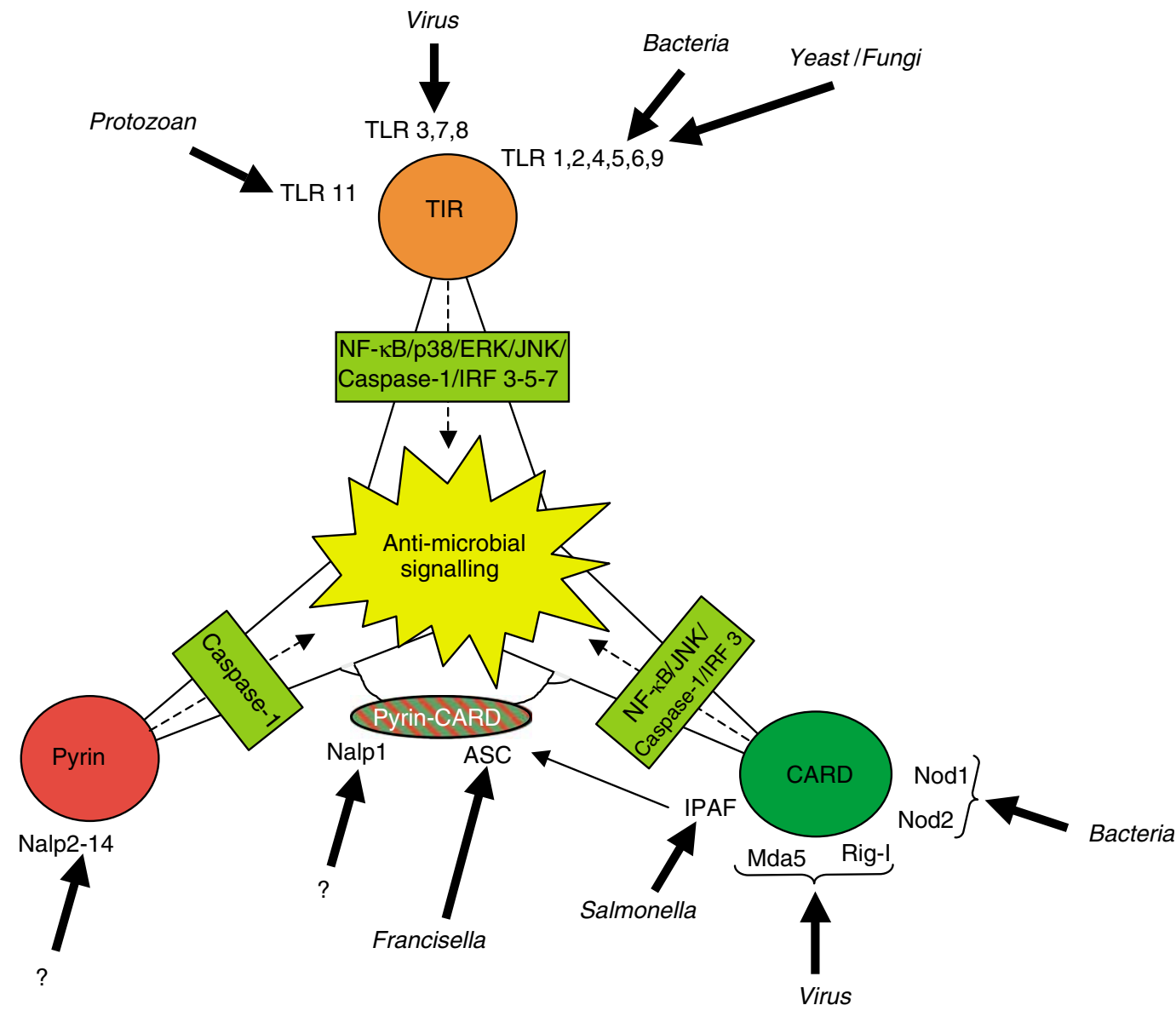

Figure 3 Schematic representation of the TIR/CARD/PYRIN antimicrobial triad. Pathways dependent on proteins displaying any of these signaling domains converge to trigger a global antimicrobial response. Innate immune molecules display only one of these domains, with the notable exception of ASC and Nalp1 (see also Figure 2), two proteins that share PYRIN and CARD domains. The green rectangle represents the principal signaling pathways triggered upon activation of each arm of the triad. It remains unknown yet what are the triggers that activate Nalp family members. Also, Salmonella has been shown to induce Ipaf- and ASC-dependent signaling, but it remains unclear if Ipaf is specific for Salmonella or if (more likely) Ipaf detects a conserved motif found in this bacterium. Similarly, ASC has been shown to mediate Ipafindependent signaling triggered by the Gram-negative bacterium Francisella, but the molecules involved in this pathway remain unidentified

molecule implicated in the canonical MyD88-dependent TLR signaling, has also been shown to participate in the Nod2 pathway, ${ }^{93}$ (iii) MDP stimulation upregulates MyD88 expression, ${ }^{133}$ (iv) MDP-stimulated macrophages induce a significant upregulation of TNF mRNA, and LPS costimulation efficiently enhances TNF mRNA translation and release. ${ }^{134}$ It is possible that all the above observations contribute, in part, to the synergistic effect of Nods on TLR signaling, and that not a single mechanism is responsible for the global effect.

The physiological importance of TLR/Nod synergy in the induction of a global response to microbial stimulus is obvious: the positive crosstalk between these pathways allows: (i) to initiate a more potent response to the microbe, and (ii) to generate a more controlled response since the maximal effect would necessitate to trigger simultaneously the two arms of the defense pathway. Global transcriptome studies will be needed to define whether this synergistic response allows only for a more intense response or if the repertoire of genes modulated by the combined action of the microbial motifs is wider than the sum of the genes induced separately by each microbial pattern alone. Importantly, in pathological conditions where Nod2 signaling is affected, such as in Crohn's disease patients carrying a homozygous NOD2fs mutation, it is clear that the Nod2/TLR synergy is impaired. ${ }^{83,86,104}$ It is tempting to speculate that in these patients, the most deleterious effect of the mutation resides in the defective response to a combined Nod2/TLR stimulus (a situation normally encountered when a whole bacteria stimulates innate immune responses) rather than solely an impaired sensing of MDP.

Another interesting aspect of the crosstalk between TLR and Nod pathways has been proposed recently by Watanabe et al. ${ }^{84}$ In their study, the authors identified an unexpected negative role of Nod2 on TLR2-mediated induction of $T_{\mathrm{H}^{1}}$ type cytokines IL-12 and IFN- $\gamma$ in a specific subpopulation of murine splenocytes (CD11 ${ }^{+}$cells). In light of all data suggesting a synergistic role of Nod ligands on TLR signaling, the results from this study appear somehow counter-intuitive. However, it is interesting to speculate that for certain stimuli and in specific cell types, TLRs and Nods could antagonize each other. In the case of the study by Watanabe, an exciting hypothesis is that Nod2 influences the balance of $T_{H^{1}} 1-/ T_{H^{2}} 2-$ type immune responses following TLR2 stimulation, and 
thereby contributes to the modulation of the adaptive immune response to bacteria. The results obtained by Watanabe and co-workers have been recently challenged by two groups investigating the responses of macrophages from either Nod2 knockout mice or Nod2fs knock-in mice (see also below). ${ }^{85,107}$ While the controversy points out that the negative effect of Nod2 on TLR2-driven signaling pathways might not be a general property in every cell type, it must be noted that the two most recent studies have not investigated the Nod2/TLR2 crosstalk in CD11b ${ }^{+}$splenocytes.

\section{Nods/Nalps}

Members of the NALP family are involved in the regulation of the inflammosome, the molecular complex responsible for the activation of caspase-1 (see Part III). Interestingly, Nod ligands MDP (Nod2), MurtriDAP (human Nod1) and FK156 (murine Nod1) have been shown to induce IL-1 $\beta$ secretion in macrophages. ${ }^{104,105}$ This suggests that Nods might be able to stimulate directly the inflammosome. In a recent study, Martinon et al. ${ }^{129}$ identified Nalp3 as an intermediate factor in MDP-induced activation of the inflammosome. It remains unclear from this study, however, if (i) Nod2 and Nalp3 are two independent systems of MDP detection, triggering NF- $\kappa \mathrm{B}$ dependent and caspase-1-dependent signaling pathways, respectively, or if (ii) Nalp3 acts downstream of Nod2 in the specific pathways leading to the inflammosome activation. In light of our current knowledge, the second hypothesis appears to be more likely. Indeed, studies on isolated peripheral blood mononuclear cells from patients homozygous for the NOD2 $1007 \mathrm{fs}$ mutation demonstrate that defective Nod2 results in abrogation of MDP-mediated IL- $1 \beta$ secretion (see Part II).

A link between Nod2 and the caspase-1 inflammosome has been indirectly suggested by a recent study by Maeda et al. ${ }^{107}$ The authors report the generation of a Nod2fs knock-in mouse that carries the same insertion mutation as the one (NOD2 $1007 \mathrm{fs}$ ) found in humans to be associated with susceptibility to Crohn's disease. Surprisingly, macrophages from these mice displayed enhanced secretion of IL-1 $\beta$ in response to MDP. However, because the amounts of secreted IL-1 $\beta$ remained very low and the results contradicts so far all reports on human cells isolated from patients carrying the NOD2 1007 fs mutation (see above), it remains difficult at this stage to interpret the results from this study.

\section{TLRs/Nalps}

ASC is a crucial CARD- and PYRIN-containing adaptor molecule implicated in Nalp-dependent induction of caspase-1 activation (see Part III). The response of isolated macrophages from $\mathrm{ASC}^{-1-}$ mice to some TLR agonists (LPS, commercial PG, lipoteichoic acid, Flagellin, R848 singlestranded RNA) has been investigated recently. It appears that ASC is dispensable for TNF secretion triggered by TLRs. ${ }^{67}$ However, strikingly, secretion of IL-1 $\beta$, IL-18 and IL- $1 \alpha$ was fully abrogated in $\mathrm{ASC}^{-/-}$macrophages stimulated with TLR agonists in presence of ATP. This observation therefore implicates ASC (and possibly Nalps, even though this remains to be characterized) in the signaling pathway linking TLRs to caspase-1 activation. However, the role of ASC in this pathway remains unclear. Indeed, while the authors propose that $\mathrm{ASC}^{-1-}$ cells fail to induce caspase-1 maturation/ activation in response to TLR stimulation, the fact that IL-1 $\alpha$ levels were also down suggests the existence of other mechanisms since pro-IL1 $\alpha$ is not a substrate of caspase- 1 . Also, interestingly, in the same study, $\mathrm{ASC}^{-1-}$ mice were reported to be resistant to LPS-induced septic shock, in a model of intraperitoneal injection. ${ }^{67}$

Except for Nalp3 (see Part III), mice deficient for members of the Nalp family have not been characterized yet. However, by using silencing RNA technology, Williams et al. ${ }^{123}$ have shown that Nalp12 is an antagonist of TLR-induced proinflammatory signals in myeloid cells. The authors show that Nalp12 binds IRAK-1, resulting in downregulation of the activity of this important molecule of the TLR signaling cascade.

\section{Conclusion}

In less than a decade, our understanding of the mechanisms by which microorganisms are detected by their mammalian host has expanded in a spectacular way, essentially via the identification of TLRs and NLRs and their downstream signaling pathways. A great challenge for the coming years will be to: (i) characterize what is the functional importance of PYRIN- and CARD-dependent pathways in innate immune sensing, (ii) identify precisely the molecular components of these signaling cascades and (iii) define the level of crosstalk between TIR-, CARD- and PYRIN-mediated signaling pathways.

An important concept that emerged from the discovery of NLRs and CARD-Helicases is that the host's innate immune system is compartmentalized. Detection systems for bacteria and viruses exist both at the cell surface and intracellularly (either in the cytosol or within intracellular vesicles). It is likely that detection of microbes in distinct cellular compartments contributes to the generation of cooperative responses to a putative pathogen. Alternatively, having distinct possible locations of microbial sensing may allow the host cell to cope with a broad array of infectious strategies (whether the microbe remains extracellular or invades the host cell). In line with these emerging concepts, one can hypothesize that another level of complexity would come with the identification of PRRs that are present in specific cellular compartments, such as the nucleus or the endoplasmic reticulum.

\section{References}

1. Lemaitre B, Nicolas E, Michaut L, Reichhart JM and Hoffmann JA (1996) The dorsoventral regulatory gene cassette spatzle/Toll/cactus controls the potent antifungal response in Drosophila adults. Cell 86: 973-983.

2. Medzhitov R, Preston-Hurlburt $P$ and Janeway Jr CA (1997) A human homologue of the Drosophila Toll protein signals activation of adaptive immunity. Nature 388: 394-397.

3. Poltorak A, He X, Smirnova I, Liu MY, Van Huffel C, Du X, Birdwell D, Alejos E, Silva M, Galanos C, Freudenberg M, Ricciardi-Castagnoli P, Layton B and Beutler B (1998) Defective LPS signaling in $\mathrm{C} 3 \mathrm{H} / \mathrm{HeJ}$ and $\mathrm{C} 57 \mathrm{BL} / 10 \mathrm{ScCr}$ mice: mutations in Trr4 gene. Science 282: 2085-2088.

4. Kawai T and Akira S (2005) Pathogen recognition with Toll-like receptors. Curr. Opin. Immunol. 17: 338-344. 
5. Choe J, Kelker MS and Wilson IA (2005) Crystal structure of human toll-like receptor 3 (TLR3) ectodomain. Science 309: 581-585.

6. Saitoh S, Akashi S, Yamada T, Tanimura N, Kobayashi M, Konno K, Matsumoto F, Fukase K, Kusumoto S, Nagai $Y$, Kusumoto $Y$, Kosugi $A$ and Miyake K (2004) Lipid A antagonist, lipid IVa, is distinct from lipid A in interaction with Toll-like receptor 4 (TLR4)-MD-2 and ligand-induced TLR4 oligomerization. Int. Immunol. 16: 961-969.

7. Smith KD, Andersen-Nissen E, Hayashi F, Strobe K, Bergman MA, Barrett SL, Cookson BT and Aderem A (2003) Toll-like receptor 5 recognizes a conserved site on flagellin required for protofilament formation and bacterial motility. Nat. Immunol. 4: 1247-1253.

8. Cornelie S, Hoebeke J, Schacht AM, Bertin B, Vicogne J, Capron M and Riveau G (2004) Direct evidence that toll-like receptor 9 (TLR9) functionally binds plasmid DNA by specific cytosine-phosphate-guanine motif recognition. J. Biol. Chem. 279: 15124-15129.

9. Philpott DJ and Girardin SE (2004) The role of Toll-like receptors and Nod proteins in bacterial infection. Mol. Immunol. 41: 1099-1108.

10. Jiang D, Liang J, Fan J, Yu S, Chen S, Luo Y, Prestwich GD, Mascarenhas MM, Garg HG, Quinn DA, Homer RJ, Goldstein DR, Bucala R, Lee PJ, Medzhitov R and Noble PW (2005) Regulation of lung injury and repair by Toll-like receptors and hyaluronan. Nat. Med. 11: 1173-1179.

11. Termeer C, Benedix F, Sleeman J, Fieber C, Voith U, Ahrens T, Miyake K, Freudenberg M, Galanos C and Simon JC (2002) Oligosaccharides of Hyaluronan activate dendritic cells via toll-like receptor 4. J. Exp. Med. 195: 99-111.

12. Ishii KJ and Akira S (2005) TLR ignores methylated RNA? Immunity 23: $111-113$.

13. Heil F, Hemmi H, Hochrein H, Ampenberger F, Kirschning C, Akira S, Lipford $\mathrm{G}$, Wagner $\mathrm{H}$ and Bauer $\mathrm{S}$ (2004) Species-specific recognition of singlestranded RNA via toll-like receptor 7 and 8. Science 303: 1526-1529.

14. Diebold SS, Kaisho T, Hemmi H, Akira S and Reis e Sousa C (2004) Innate antiviral responses by means of TLR7-mediated recognition of singlestranded RNA. Science 303: 1529-1531.

15. Kariko K, Buckstein M, Ni H and Weissman D (2005) Suppression of RNA recognition by Toll-like receptors: the impact of nucleoside modification and the evolutionary origin of RNA. Immunity 23: 165-175.

16. Kariko K, Ni H, Capodici J, Lamphier M and Weissman D (2004) mRNA is an endogenous ligand for Toll-like receptor 3. J. Biol. Chem. 279: 12542-12550.

17. Barrat FJ, Meeker T, Gregorio J, Chan JH, Uematsu S, Akira S, Chang B, Duramad $O$ and Coffman RL (2005) Nucleic acids of mammalian origin can act as endogenous ligands for Toll-like receptors and may promote systemic lupus erythematosus. J. Exp. Med. 202: 1131-1139.

18. Hayashi F, Smith KD, Ozinsky A, Hawn TR, Yi EC, Goodlett DR, Eng JK, Akira S, Underhill DM and Aderem A (2001) The innate immune response to bacterial flagellin is mediated by Toll-like receptor 5 . Nature 410 : 1099-1103.

19. Andersen-Nissen E, Smith KD, Strobe KL, Barrett SL, Cookson BT, Logan SM and Aderem A (2005) Evasion of Toll-like receptor 5 by flagellated bacteria. Proc. Natl. Acad. Sci. USA 102: 9247-9252.

20. Yarovinsky F, Zhang D, Andersen JF, Bannenberg GL, Serhan CN, Hayden MS, Hieny S, Sutterwala FS, Flavell RA, Ghosh S and Sher A (2005) TLR11 activation of dendritic cells by a protozoan profilin-like protein. Science 308 : 1626-1629.

21. Zhang D, Zhang G, Hayden MS, Greenblatt MB, Bussey C, Flavell RA and Ghosh S (2004) A toll-like receptor that prevents infection by uropathogenic bacteria. Science 303: 1522-1526.

22. Ku CL, Yang K, Bustamante J, Puel A, von Bernuth $\mathrm{H}$, Santos OF, Lawrence $\mathrm{T}$, Chang HH, Al-Mousa H, Picard C and Casanova JL (2005) Inherited disorders of human Toll-like receptor signaling: immunological implications. Immunol. Rev. 203: 10-20.

23. Kawai T, Adachi O, Ogawa T, Takeda K and Akira S (1999) Unresponsiveness of MyD88-deficient mice to endotoxin. Immunity 11: 115-122.

24. Kaisho T, Takeuchi O, Kawai T, Hoshino K and Akira S (2001) Endotoxininduced maturation of MyD88-deficient dendritic cells. J. Immunol. 166: 56885694.

25. Stockinger S, Reutterer B, Schaljo B, Schellack C, Brunner S, Materna T, Yamamoto M, Akira S, Taniguchi T, Murray PJ, Muller M and Decker T (2004) IFN regulatory factor 3-dependent induction of type I IFNs by intracellular bacteria is mediated by a TLR- and Nod2-independent mechanism. J. Immunol. 173: 7416-7425.

26. Moynagh PN (2005) TLR signalling and activation of IRFs: revisiting old friends from the NF-kappaB pathway. Trends. Immunol. 26: 469-476.

27. Liu YJ (2005) IPC: professional type 1 interferon-producing cells and plasmacytoid dendritic cell precursors. Annu. Rev. Immunol. 23: 275-306.

28. Honda K, Ohba Y, Yanai H, Negishi H, Mizutani T, Takaoka A, Taya C and Taniguchi T (2005) Spatiotemporal regulation of MyD88-IRF-7 signalling for robust type-l interferon induction. Nature 434: 1035-1040.

29. Uematsu S, Sato S, Yamamoto M, Hirotani T, Kato H, Takeshita F, Matsuda M, Coban C, Ishii KJ, Kawai T, Takeuchi O and Akira S (2005) Interleukin-1 receptor-associated kinase-1 plays an essential role for Toll-like receptor (TLR)7- and TLR9-mediated interferon-\{alpha\} induction. J. Exp. Med. 201: 915-923.

30. Takaoka A, Yanai H, Kondo S, Duncan G, Negishi H, Mizutani T, Kano S, Honda K, Ohba Y, Mak TW and Taniguchi T (2005) Integral role of IRF-5 in the gene induction programme activated by Toll-like receptors. Nature 434: 243-249.

31. Schoenemeyer A, Barnes BJ, Mancl ME, Latz E, Goutagny N, Pitha PM, Fitzgerald KA and Golenbock DT (2005) The interferon regulatory factor, IRF5, is a central mediator of toll-like receptor 7 signaling. J. Biol. Chem. 280: 17005-17012.

32. Gautier G, Humbert M, Deauvieau F, Scuiller M, Hiscott J, Bates EE, Trinchieri G, Caux C and Garrone P (2005) A type I interferon autocrineparacrine loop is involved in Toll-like receptor-induced interleukin-12p70 secretion by dendritic cells. J. Exp. Med. 201: 1435-1446.

33. Liew FY, Xu D, Brint EK and O'Neill LA (2005) Negative regulation of toll-like receptor-mediated immune responses. Nat. Rev. Immunol. 5: 446-458.

34. Garlanda C, Riva F, Polentarutti N, Buracchi C, Sironi M, De Bortoli M, Muzio M, Bergottini R, Scanziani E, Vecchi A, Hirsch E and Mantovani A (2004) Intestinal inflammation in mice deficient in Tir8, an inhibitory member of the IL1 receptor family. Proc. Natl. Acad. Sci. USA 101: 3522-3526.

35. Negishi H, Ohba Y, Yanai H, Takaoka A, Honma K, Yui K, Matsuyama T, Taniguchi T and Honda K (2005) Negative regulation of Toll-like-receptor signaling by IRF-4. Proc. Natl. Acad. Sci. USA 102: 15989-15994.

36. Bowie AG, Zhan J and Marshall WL (2004) Viral appropriation of apoptotic and NF-kappaB signaling pathways. J. Cell. Biochem. 91: 1099-1108.

37. Schroder NW and Schumann RR (2005) Single nucleotide polymorphisms of Toll-like receptors and susceptibility to infectious disease. Lancet. Infect. Dis. 5: $156-164$.

38. Hawn TR, Verbon A, Lettinga KD, Zhao LP, Li SS, Laws RJ, Skerrett SJ, Beutler B, Schroeder L, Nachman A, Ozinsky A, Smith KD and Aderem A (2003) A common dominant TLR5 stop codon polymorphism abolishes flagellin signaling and is associated with susceptibility to legionnaires' disease. J. Exp. Med. 198: 1563-1572.

39. Sebastiani G, Leveque G, Lariviere L, Laroche L, Skamene E, Gros P and Malo $D(2000)$ Cloning and characterization of the murine toll-like receptor 5 (Tlr5) gene: sequence and mRNA expression studies in Salmonellasusceptible MOLF/Ei mice. Genomics 64: 230-240.

40. Hawn TR, Wu H, Grossman JM, Hahn BH, Tsao BP and Aderem A (2005) A stop codon polymorphism of Toll-like receptor 5 is associated with resistance to systemic lupus erythematosus. Proc. Natl. Acad. Sci. USA 102: 10593-10597.

41. Kufer TA, Fritz JH and Philpott DJ (2005) NACHT-LRR proteins (NLRs) in bacterial infection and immunity. Trends Microbiol. 13: 381-388.

42. Girardin SE, Boneca IG, Viala J, Chamaillard M, Labigne A, Thomas G, Philpott DJ and Sansonetti PJ (2003) Nod2 is a general sensor of peptidoglycan through muramyl dipeptide (MDP) detection. J. Biol. Chem. 278: 8869-8872.

43. Girardin SE, Boneca IG, Carneiro LA, Antignac A, Jehanno M, Viala J, Tedin K, Taha MK, Labigne A, Zahringer U, Coyle AJ, DiStefano PS, Bertin J, Sansonetti PJ and Philpott DJ (2003) Nod1 detects a unique muropeptide from gram-negative bacterial peptidoglycan. Science 300: 1584-1587.

44. Inohara N, Ogura Y, Fontalba A, Gutierrez O, Pons F, Crespo J, Fukase K, Inamura S, Kusumoto S, Hashimoto M, Foster SJ, Moran AP, FernandezLuna JL and Nunez G (2003) Host recognition of bacterial muramyl dipeptide mediated through NOD2. Implications for Crohn's disease. J. Biol. Chem. 278: 5509-5512. 
45. Chamaillard M, Hashimoto M, Horie Y, Masumoto J, Qiu S, Saab L, Ogura Y, Kawasaki A, Fukase K, Kusumoto S, Valvano MA, Foster SJ, Mak TW, Nunez $G$ and Inohara N (2003) An essential role for NOD1 in host recognition of bacterial peptidoglycan containing diaminopimelic acid. Nat. Immunol. 4: 702-707.

46. Travassos LH, Girardin SE, Philpott DJ, Blanot D, Nahori MA, Werts $C$ and Boneca IG (2004) Toll-like receptor 2-dependent bacterial sensing does not occur via peptidoglycan recognition. EMBO Rep. 5: 1000-1006.

47. Dziarski R and Gupta D (2005) Staphylococcus aureus peptidoglycan is a toll-like receptor 2 activator: a reevaluation. Infect. Immun. 73: 5212-5216.

48. Inamura S, Fujimoto Y, Kawasaki A, Shiokawa Z, Woelk E, Heine H, Lindner B, Inohara N, Kusumoto S and Fukase K (2006) Synthesis of peptidoglycan fragments and evaluation of their biological activity. Org. Biomol. Chem. 4: 232-242.

49. Boneca IG (2005) The role of peptidoglycan in pathogenesis. Curr. Opin. Microbiol. 8: 46-53.

50. Girardin SE, Travassos LH, Herve M, Blanot D, Boneca IG, Philpott DJ, Sansonetti PJ and Mengin-Lecreulx D (2003) Peptidoglycan molecular requirements allowing detection by Nod1 and Nod2. J. Biol. Chem. 278: 41702-41708.

51. Chamaillard M, Philpott D, Girardin SE, Zouali H, Lesage S, Chareyre F, Bui TH, Giovannini M, Zaehringer U, Penard-Lacronique V, Sansonetti PJ, Hugot JP and Thomas G (2003) Gene-environment interaction modulated by allelic heterogeneity in inflammatory diseases. Proc. Natl. Acad. Sci. USA 100: $3455-3460$

52. Magalhaes JG, Philpott DJ, Nahori MA, Jehanno M, Fritz J, Bourhis LL, Viala J, Hugot JP, Giovannini M, Bertin J, Lepoivre M, Mengin-Lecreulx D, Sansonetti PJ and Girardin SE (2005) Murine Nod1 but not its human orthologue mediates innate immune detection of tracheal cytotoxin. EMBO Rep. 6: 1201-1207.

53. Goldman WE and Cookson BT (1988) Structure and functions of the Bordetella tracheal cytotoxin. Tokai. J. Exp. Clin. Med. 13 (Suppl): 187-191.

54. Girardin SE, Jehanno M, Mengin-Lecreulx D, Sansonetti PJ, Alzari PM and Philpott DJ (2005) Identification of the critical residues involved in peptidoglycan detection by nod1. J. Biol. Chem. 280: 38648-38656.

55. Tanabe T, Chamaillard M, Ogura Y, Zhu L, Qiu S, Masumoto J, Ghosh P, Moran A, Predergast MM, Tromp G, Williams CJ, Inohara N and Nunez G (2004) Regulatory regions and critical residues of NOD2 involved in muramyl dipeptide recognition. EMBO J. 23: 1587-1597.

56. Girardin SE, Tournebize R, Mavris M, Page AL, Li X, Stark GR, Bertin J, DiStefano PS, Yaniv M, Sansonetti PJ and Philpott DJ (2001) CARD4/Nod1 mediates NF-kappaB and JNK activation by invasive Shigella flexneri. EMBO Rep. 2: 736-742.

57. Kim JG, Lee SJ and Kagnoff MF (2004) Nod1 is an essential signal transducer in intestinal epithelial cells infected with bacteria that avoid recognition by tolllike receptors. Infect. Immun. 72: 1487-1495.

58. Travassos LH, Carneiro LA, Girardin SE, Boneca IG, Lemos R, Bozza MT Domingues RC, Coyle AJ, Bertin J, Philpott DJ and Plotkowski MC (2005) Nod1 participates in the innate immune response to Pseudomonas aeruginosa. J. Biol. Chem. 280: 36714-36718.

59. Opitz B, Forster S, Hocke AC, Maass M, Schmeck B, Hippenstiel S, Suttorp N and Krull M (2005) Nod1-mediated endothelial cell activation by Chlamydophila pneumoniae. Circ. Res. 96: 319-326.

60. Viala J, Chaput C, Boneca IG, Cardona A, Girardin SE, Moran AP, Athman R, Memet S, Huerre MR, Coyle AJ, DiStefano PS, Sansonetti PJ, Labigne A, Bertin J, Philpott DJ and Ferrero RL (2004) Nod1 responds to peptidoglycan delivered by the Helicobacter pylori cag pathogenicity island. Nat. Immunol. 5 : 1166-1174.

61. Opitz B, Puschel A, Schmeck B, Hocke AC, Rosseau S, Hammerschmidt S, Schumann RR, Suttorp N and Hippenstiel S (2004) Nucleotide-binding oligomerization domain proteins are innate immune receptors for internalized Streptococcus pneumoniae. J. Biol. Chem. 279: 36426-36432.

62. Ferwerda G, Girardin SE, Kullberg B-J, de Jong D, Lagenberg DML, van Crevel R, Adema GJ, Ottenhoff THM, van der Meer JWM and Netea MG (2005) Nod2 and TLR2 are two non-redundant recognition systems of mycobacterium tuberculosis. PLoS Pathogens 1: 280-285.

63. Kanazawa N, Okafuji I, Kambe N, Nishikomori R, Nakata-Hizume M, Nagai S, Fuji A, Yuasa T, Manki A, Sakurai Y, Nakajima M, Kobayashi H, Fujiwara I, Tsutsumi H, Utani A, Nishigori C, Heike T, Nakahata T and Miyachi Y (2005)
Early-onset sarcoidosis and CARD15 mutations with constitutive nuclear factor-kappaB activation: common genetic etiology with Blau syndrome. Blood 105: 1195-1197.

64. Hisamatsu T, Suzuki M, Reinecker HC, Nadeau WJ, McCormick BA and Podolsky DK (2003) CARD15/NOD2 functions as an antibacterial factor in human intestinal epithelial cells. Gastroenterology 124: 993-1000.

65. Ogura Y, Lala S, Xin W, Smith E, Dowds TA, Chen FF, Zimmermann E, Tretiakova M, Cho JH, Hart J, Greenson JK, Keshav S and Nunez G (2003) Expression of NOD2 in Paneth cells: a possible link to Crohn's ileitis. Gut 52: 1591-1597.

66. Wehkamp J, Harder J, Weichenthal M, Schwab M, Schaffeler E, Schlee M, Herrlinger KR, Stallmach A, Noack F, Fritz P, Schroder JM, Bevins CL, Fellermann K and Stange EF (2004) NOD2 (CARD15) mutations in Crohn's disease are associated with diminished mucosal alpha-defensin expression. Gut 53: 1658-1664.

67. Mariathasan S, Newton K, Monack DM, Vucic D, French DM, Lee WP, RooseGirma M, Erickson S and Dixit VM (2004) Differential activation of the inflammasome by caspase-1 adaptors ASC and Ipaf. Nature 430: 213-218.

68. Diebold SS, Montoya M, Unger H, Alexopoulou L, Roy P, Haswell LE, Al-Shamkhani A, Flavell R, Borrow P and Reis e Sousa C (2003) Viral infection switches non-plasmacytoid dendritic cells into high interferon producers. Nature 424: 324-328.

69. Yoneyama M, Kikuchi M, Natsukawa T, Shinobu N, Imaizumi T, Miyagishi M, Taira K, Akira S and Fujita T (2004) The RNA helicase RIG-I has an essential function in double-stranded RNA-induced innate antiviral responses. Nat. Immunol. 5: 730-737.

70. Kang DC, Gopalkrishnan RV, Lin L, Randolph A, Valerie K, Pestka S and Fisher PB (2004) Expression analysis and genomic characterization of human melanoma differentiation associated gene-5, mda-5: a novel type I interferonresponsive apoptosis-inducing gene. Oncogene 23: 1789-1800.

71. Yoneyama M, Kikuchi M, Matsumoto K, Imaizumi T, Miyagishi M, Taira K, Foy E, Loo YM, Gale Jr M, Akira S, Yonehara S, Kato A and Fujita T (2005) Shared and unique functions of the DExD/H-box helicases RIG-I, MDA5, and LGP2 in antiviral innate immunity. J. Immunol. 175: 2851-2858.

72. Rothenfusser S, Goutagny N, Diperna G, Gong M, Monks BG, Schoenemeyer A, Yamamoto M, Akira S and Fitzgerald KA (2005) The RNA Helicase Lgp2 inhibits TLR-independent sensing of viral replication by retinoic acid-inducible gene-I. J. Immunol. 175: 5260-5268.

73. Kato H, Sato S, Yoneyama M, Yamamoto M, Uematsu S, Matsui K, Tsujimura T, Takeda K, Fujita T, Takeuchi O and Akira S (2005) Cell type-specific involvement of RIG-I in antiviral response. Immunity 23: 19-28.

74. Andrejeva J, Childs KS, Young DF, Carlos TS, Stock N, Goodbourn S and Randall RE (2004) The V proteins of paramyxoviruses bind the IFN-inducible RNA helicase, mda-5, and inhibit its activation of the IFN-beta promoter. Proc. Natl. Acad. Sci. USA 101: 17264-17269.

75. Sumpter Jr R, Loo YM, Foy E, Li K, Yoneyama M, Fujita T, Lemon SM and Gale Jr M (2005) Regulating intracellular antiviral defense and permissiveness to hepatitis $C$ virus RNA replication through a cellular RNA helicase, RIG-I. J. Virol. 79: 2689-2699.

76. Gale Jr M and Foy EM (2005) Evasion of intracellular host defence by hepatitis $C$ virus. Nature 436: $939-945$.

77. Philpott DJ, Yamaoka S, Israel A and Sansonetti PJ (2000) Invasive Shigella flexneri activates NF-kappa B through a lipopolysaccharide-dependent innate intracellular response and leads to IL-8 expression in epithelial cells. J. Immunol. 165: 903-914.

78. Fritz JH, Girardin SE, Fitting C, Werts C, Mengin-Lecreulx D, Caroff M, Cavaillon JM, Philpott DJ and Adib-Conquy M (2005) Synergistic stimulation of human monocytes and dendritic cells by Toll-like receptor 4 and NOD1- and NOD2-activating agonists. Eur. J. Immunol. 35: 2459-2470.

79. Lu C, Wang A, Wang L, Dorsch M, Ocain TD and Xu Y (2005) Nucleotide binding to CARD12 and its role in CARD12-mediated caspase-1 activation. Biochem. Biophys. Res. Commun. 331: 1114-1119.

80. Kobayashi K, Inohara N, Hernandez LD, Galan JE, Nunez G, Janeway CA, Medzhitov R and Flavell RA (2002) RICK/Rip2/CARDIAK mediates signalling for receptors of the innate and adaptive immune systems. Nature 416: 194-199.

81. Abbott DW, Wilkins A, Asara JM and Cantley LC (2004) The Crohn's disease protein, NOD2, requires RIP2 in order to induce ubiquitinylation of a novel site on NEMO. Curr. Biol. 14: 2217-2227. 
82. Barnich N, Aguirre JE, Reinecker HC, Xavier R and Podolsky DK (2005) Membrane recruitment of NOD2 in intestinal epithelial cells is essential for nuclear factor-\{kappa\}B activation in muramyl dipeptide recognition. J. Cell. Biol. 170: 21-26.

83. Li J, Moran T, Swanson E, Julian C, Harris J, Bonen DK, Hedl M, Nicolae DL, Abraham C and Cho JH (2004) Regulation of IL-8 and IL-1beta expression in Crohn's disease associated NOD2/CARD15 mutations. Hum. Mol. Genet. 13: 1715-1725.

84. Watanabe T, Kitani A, Murray PJ and Strober W (2004) NOD2 is a negative regulator of Toll-like receptor 2-mediated T helper type 1 responses. Nat. Immunol. 5: 800-808.

85. Kobayashi KS, Chamaillard M, Ogura Y, Henegariu O, Inohara N, Nunez G and Flavell RA (2005) Nod2-dependent regulation of innate and adaptive immunity in the intestinal tract. Science 307: 731-734.

86. van Heel DA, Ghosh S, Hunt KA, Mathew CG, Forbes A, Jewell DP and Playford RJ (2005) Synergy between TLR9 and NOD2 innate immune responses is lost in genetic Crohn's disease. Gut. 54: 1553-1557.

87. van Heel DA, Ghosh S, Butler M, Hunt KA, Lundberg AM, Ahmad T, McGovern DP, Onnie C, Negoro K, Goldthorpe S, Foxwell BM, Mathew CG, Forbes A, Jewell DP and Playford RJ (2005) Muramyl dipeptide and toll-like receptor sensitivity in NOD2-associated Crohn's disease. Lancet 365: 1794-1796.

88. Traub S, Kubasch N, Morath S, Kresse M, Hartung T, Schmidt RR and Hermann C (2004) Structural requirements of synthetic muropeptides to synergize with lipopolysaccharide in cytokine induction. J. Biol. Chem. 279: 8694-8700.

89. van Heel DA, Ghosh S, Butler M, Hunt K, Foxwell BM, Mengin-Lecreulx D and Playford RJ (2005) Synergistic enhancement of Toll-like receptor responses by NOD1 activation. Eur. J. Immunol. 35: 2471-2476.

90. Netea MG, Azam T, Ferwerda G, Girardin SE, Walsh M, Park JS, Abraham E, Kim JM, Yoon DY, Dinarello CA and Kim SH (2005) IL-32 synergizes with nucleotide oligomerization domain (NOD) 1 and NOD2 ligands for IL-1\{beta\} and IL-6 production through a caspase 1-dependent mechanism. Proc. Natl. Acad. Sci. USA. 102: 16309-16314.

91. Li L, Bin LH, Li F, Liu Y, Chen D, Zhai Z and Shu HB (2005) TRIP6 is a RIP2associated common signaling component of multiple NF-kappaB activation pathways. J. Cell. Sci. 118: 555-563.

92. Barnich N, Hisamatsu T, Aguirre JE, Xavier R, Reinecker HC and Podolsky DK (2005) GRIM-19 interacts with nucleotide oligomerization domain 2 and serves as downstream effector of anti-bacterial function in intestinal epithelial cells. J. Biol. Chem. 280: 19021-19026.

93. Chen CM, Gong Y, Zhang M and Chen JJ (2004) Reciprocal crosstalk between Nod2 and TAK1 signaling pathways. J. Biol. Chem. 279: 25876-25882.

94. McDonald C, Chen FF, Ollendorff V, Ogura Y, Marchetto S, Lecine P, Borg JP and Nunez $G$ (2005) A role for erbin in the regulation of NOD2-dependent NF-kappa B signaling. J. Biol. Chem. 280: 40301-40309.

95. Kawai T, Takahashi K, Sato S, Coban C, Kumar H, Kato H, Ishii KJ, Takeuchi $O$ and Akira S (2005) IPS-1, an adaptor triggering RIG-I- and Mda5-mediated type I interferon induction. Nat. Immunol. 6: 981-988.

96. Seth RB, Sun L, Ea CK and Chen ZJ (2005) Identification and characterization of MAVS, a mitochondrial antiviral signaling protein that activates NF-kappaB and IRF 3. Cell 122: 669-682.

97. Meylan E, Curran J, Hofmann K, Moradpour D, Binder M, Bartenschlager R and Tschopp $\mathrm{J}(2005)$ Cardif is an adaptor protein in the RIG-I antiviral pathway and is targeted by hepatitis $C$ virus. Nature 437: 1167-1172.

98. Xu LG, Wang YY, Han KJ, Li LY, Zhai Z and Shu HB (2005) VISA is an adapter protein required for virus-triggered IFN-beta signaling. Mol. Cell 19: 727-740.

99. Balachandran S, Thomas E and Barber GN (2004) A FADD-dependent innate immune mechanism in mammalian cells. Nature 432: 401-405.

100. Breiman A, Grandvaux N, Lin R, Ottone C, Akira S, Yoneyama M, Fujita T, Hiscott $J$ and Meurs EF (2005) Inhibition of RIG-I-dependent signaling to the interferon pathway during hepatitis $C$ virus expression and restoration of signaling by IKKepsilon. J. Virol. 79: 3969-3978.

101. Foy E, Li K, Sumpter Jr R, Loo YM, Johnson CL, Wang C, Fish PM, Yoneyama M, Fujita T, Lemon SM and Gale Jr M (2005) Control of antiviral defenses through hepatitis $C$ virus disruption of retinoic acid-inducible gene-I signaling. Proc. Natl. Acad. Sci. USA 102: 2986-2991.
102. Li K, Foy E, Ferreon JC, Nakamura M, Ferreon AC, Ikeda M, Ray SC, Gale Jr $M$ and Lemon SM (2005) Immune evasion by hepatitis $C$ virus NS3/4A protease-mediated cleavage of the Toll-like receptor 3 adaptor protein TRIF. Proc. Natl. Acad. Sci. USA 102: 2992-2997.

103. Hugot JP, Chamaillard M, Zouali H, Lesage S, Cezard JP, Belaiche J, Almer S, Tysk C, O'Morain CA, Gassull M, Binder V, Finkel $Y$, Cortot A, Modigliani R, Laurent-Puig P, Gower-Rousseau C, Macry J, Colombel JF, Sahbatou M and Thomas G (2001) Association of NOD2 leucine-rich repeat variants with susceptibility to Crohn's disease. Nature 411: 599-603.

104. Netea MG, Ferwerda G, de Jong DJ, Werts C, Boneca IG, Jehanno M, Van Der Meer JW, Mengin-Lecreulx D, Sansonetti PJ, Philpott DJ, Dharancy $S$ and Girardin SE (2005) The Frameshift Mutation in Nod2 Results in Unresponsiveness Not Only to Nod2- but Also Nod1-activating Peptidoglycan Agonists. J. Biol. Chem. 280: 35859-35867.

105. Netea MG, Ferwerda G, de Jong DJ, Girardin SE, Kullberg BJ and van der Meer JW (2005) NOD2 3020insC mutation and the pathogenesis of Crohn's disease: impaired IL-1beta production points to a loss-of-function phenotype. Neth. J. Med. 63: 305-308.

106. Netea MG, Kullberg BJ, de Jong DJ, Franke B, Sprong T, Naber TH, Drenth JP and Van der Meer JW (2004) NOD2 mediates anti-inflammatory signals induced by TLR2 ligands: implications for Crohn's disease. Eur. J. Immunol. 34: 2052-2059.

107. Maeda S, Hsu LC, Liu H, Bankston LA, limura M, Kagnoff MF, Eckmann L and Karin M (2005) Nod2 mutation in Crohn's disease potentiates NF-kappaB activity and IL-1beta processing. Science 307: 734-738.

108. Holler E, Rogler G, Herfarth H, Brenmoehl J, Wild PJ, Hahn J, Eissner G, Scholmerich $\mathrm{J}$ and Andreesen R (2004) Both donor and recipient NOD2/CARD15 mutations associate with transplant-related mortality and GvHD following allogeneic stem cell transplantation. Blood 104: 889-894.

109. Miceli-Richard C, Lesage S, Rybojad M, Prieur AM, Manouvrier-Hanu S, Hafner R, Chamaillard M, Zouali H, Thomas G and Hugot JP (2001) CARD15 mutations in Blau syndrome. Nat. Genet. 29: 19-20.

110. McGovern DP, Hysi P, Ahmad T, van Heel DA, Moffatt MF, Carey A, Cookson WO and Jewell DP (2005) Association between a complex insertion/deletion polymorphism in NOD1 (CARD4) and susceptibility to inflammatory bowel disease. Hum. Mol. Genet. 14: 1245-1250.

111. Hysi P, Kabesch M, Moffatt MF, Schedel M, Carr D, Zhang Y, Boardman B, von Mutius E, Weiland SK, Leupold W, Fritzsch C, Klopp N, Musk AW, James A, Nunez G, Inohara N and Cookson WO (2005) NOD1 variation, immunoglobulin $E$ and asthma. Hum. Mol. Genet. 14: 935-941.

112. Weidinger S, Klopp N, Rummler L, Wagenpfeil S, Novak N, Baurecht HJ, Groer W, Darsow U, Heinrich J, Gauger A, Schafer T, Jakob T, Behrendt H, Wichmann HE, Ring J and Illig T (2005) Association of NOD1 polymorphisms with atopic eczema and related phenotypes. J. Allergy Clin. Immunol. 116 177-184.

113. Zouali H, Lesage S, Merlin F, Cezard JP, Colombel JF, Belaiche J, Almer S, Tysk C, O'Morain C, Gassull M, Christensen S, Finkel Y, Modigliani R, GowerRousseau C, Macry J, Chamaillard M, Thomas G and Hugot JP (2003) CARD4/NOD1 is not involved in inflammatory bowel disease. Gut 52: 71-74.

114. Martinon F, Hofmann $\mathrm{K}$ and Tschopp J (2001) The pyrin domain: a possible member of the death domain-fold family implicated in apoptosis and inflammation. Curr. Biol. 11: R118-R120.

115. Hoffman HM, Mueller JL, Broide DH, Wanderer AA and Kolodner RD (2001) Mutation of a new gene encoding a putative pyrin-like protein causes familia cold autoinflammatory syndrome and Muckle-Wells syndrome. Nat. Genet. 29: 301-305.

116. Chae JJ, Komarow HD, Cheng J, Wood G, Raben N, Liu PP and Kastner DL (2003) Targeted disruption of pyrin, the FMF protein, causes heightened sensitivity to endotoxin and a defect in macrophage apoptosis. Mol. Cell 11: 591-604.

117. Yu JW, Wu J, Zhang Z, Datta P, Ibrahimi I, Taniguchi S, Sagara J, FernandesAlnemri T and Alnemri ES (2006) Cryopyrin and pyrin activate caspase-1, but not NF-kappaB, via ASC oligomerization. Cell Death Differ. 13: 236-249.

118. Stehlik C, Lee SH, Dorfleutner A, Stassinopoulos A, Sagara J and Reed JC (2003) Apoptosis-associated speck-like protein containing a caspase recruitment domain is a regulator of procaspase-1 activation. J. Immunol. 171: 6154-6163. 
119. Mariathasan S, Weiss DS, Dixit VM and Monack DM (2005) Innate immunity against Francisella tularensis is dependent on the ASC/caspase-1 axis. J. Exp. Med. 202: 1043-1049.

120. Grenier JM, Wang L, Manji GA, Huang WJ, Al-Garawi A, Kelly R, Carlson A Merriam S, Lora JM, Briskin M, DiStefano PS and Bertin J (2002) Functional screening of five PYPAF family members identifies PYPAF5 as a novel regulator of NF-kappaB and caspase-1. FEBS Lett. 530: 73-78.

121. Wang L, Manji GA, Grenier JM, Al-Garawi A, Merriam S, Lora JM, Geddes BJ, Briskin M, DiStefano PS and Bertin J (2002) PYPAF7, a novel PYRINcontaining Apaf1-like protein that regulates activation of NF-kappa B and caspase-1-dependent cytokine processing. J. Biol. Chem. 277: 29874-29880

122. O'Connor Jr W, Harton JA, Zhu X, Linhoff MW and Ting JP (2003) Cutting edge: CIAS1/cryopyrin/PYPAF1/NALP3/CATERPILLER 1.1 is an inducible inflammatory mediator with NF-kappa B suppressive properties. J. Immunol. 171: 6329-6333.

123. Williams KL, Lich JD, Duncan JA, Reed W, Rallabhandi P, Moore C, Kurtz S, Coffield VM, Accavitti-Loper MA, Su L, Vogel SN, Braunstein M and Ting JP (2005) The CATERPILLER protein Monarch-1 is an antagonist of TLR, TNFalpha, and M. tuberculosis-induced pro-inflammatory signals. J. Biol. Chem. 280: 39914-39924.

124. Tschopp J, Martinon F and Burns K (2003) NALPs: a novel protein family involved in inflammation. Nat. Rev. Mol. Cell. Biol. 4: 95-104.

125. Martinon F, Burns $\mathrm{K}$ and Tschopp J (2002) The inflammasome: a molecular platform triggering activation of inflammatory caspases and processing of prolL-beta. Mol. Cell 10: 417-426.

126. Agostini L, Martinon F, Burns K, McDermott MF, Hawkins PN and Tschopp J (2004) NALP3 forms an IL-1beta-processing inflammasome with increased activity in Muckle-Wells autoinflammatory disorder. Immunity 20: 319-325.
127. Neven B, Callebaut I, Prieur AM, Feldmann J, Bodemer C, Lepore L, Derfalvi B, Benjaponpitak S, Vesely R, Sauvain MJ, Oertle S, Allen R, Morgan G, Borkhardt A, Hill C, Gardner-Medwin J, Fischer A and de Saint Basile G (2004) Molecular basis of the spectral expression of CIAS1 mutations associated with phagocytic cell-mediated autoinflammatory disorders CINCA/ NOMID, MWS, and FCU. Blood 103: 2809-2815

128. van Duist MM, Albrecht M, Podswiadek M, Giachino D, Lengauer T, Punzi L and De Marchi M (2005) A new CARD15 mutation in Blau syndrome. Eur. J. Hum. Genet. 13: 742-747.

129. Martinon F, Agostini L, Meylan E and Tschopp J (2004) Identification of bacterial muramyl dipeptide as activator of the NALP3/cryopyrin inflammasome. Curr. Biol. 14: 1929-1934.

130. Kanneganti TD, Ozoren N, Body-Malapel M, Amer A, Park JH, Franchi L, Whitfield J, Barchet W, Colonna M, Vandenabeele P, Bertin J, Coyle A, Grant EP, Akira S and Nunez G (2006) Bacterial RNA and small antiviral compounds activate caspase-1 through cryopyrin/Nalp3. Nature January 11 (Epub ahead of print).

131. Mariathasan S, Weiss DS, Newton K, McBride J, O'Rourke K, Roose-Girma M, Lee WP, Weinrauch Y, Monack DM and Dixit VM (2006) Cryopyrin activates the inflammasome in response to toxins and ATP. Nature January 11 (Epub ahead of print).

132. Martinon F, Petrilli V, Mayor A, Tardivel A and Tschopp J (2006) Goutassociated uric acid crystals activate the NALP3 inflammasome. Nature January 11 (Epub ahead of print).

133. Yang S, Tamai R, Akashi S, Takeuchi O, Akira S, Sugawara S and Takada H (2001) Synergistic effect of muramyldipeptide with lipopolysaccharide or lipoteichoic acid to induce inflammatory cytokines in human monocytic cells in culture. Infect. Immun. 69: 2045-2053.

134. Wolfert MA, Murray TF, Boons GJ and Moore JN (2002) The origin of the synergistic effect of muramyl dipeptide with endotoxin and peptidoglycan. J. Biol. Chem. 277: 39179-39186. 